GA-A15935

\title{
PRELIMINARY RESULTS FROM BENCH-SCALE TESTING OF A SULFUR-IODINE THERMOCHEMICAL WATER-SPLITTING CYCLE
}

\author{
by \\ D. O'KEEFE, C. ALLEN, G. BESENBRUCH, K. MCCORKLE, \\ J. NORMAN, and R. SHARP
}

JULY 1980 


\section{DISCLAIMER}

This report was prepared as an account of work sponsored by an agency of the United States Government. Neither the United States Government nor any agency Thereof, nor any of their employees, makes any warranty, express or implied, or assumes any legal liability or responsibility for the accuracy, completeness, or usefulness of any information, apparatus, product, or process disclosed, or represents that its use would not infringe privately owned rights. Reference herein to any specific commercial product, process, or service by trade name, trademark, manufacturer, or otherwise does not necessarily constitute or imply its endorsement, recommendation, or favoring by the United States Government or any agency thereof. The views and opinions of authors expressed herein do not necessarily state or reflect those of the United States Government or any agency thereof. 


\section{DISCLAIMER}

Portions of this document may be illegible in electronic image products. Images are produced from the best available original document. 
This report was prepared as an account of work sponsored by an agency of the United States Government. Neither the United States Government nor any agency thereof, nor any of their employees, makes any warranty, express or implied, or assumes any legal liability or responsibility for the accuracy, completeness, or usefulness of any information, apparatus, product, or process disclosed, or represents that its use would not infringe privately owned rights. Reference herein to any specific commercial product, process, or service by trade name, trademark, manufacturer, or otherwise, does not necessarily constitute or imply its endorsement, recommendation, or favoring by the United States Government or any agency thereof. The views and opinions of authors expressed herein do not necessarily state or reflect those of the United States Government or any agency thereof. 
GA-A15935

\title{
PRELIMINARY RESULTS FROM BENCH-SCALE TESTING OF A SULFUR-IODINE THERMOCHEMICAL WATER-SPLITTING CYCLE
}

\author{
by \\ D. O'KeEFE, C. ALLEN, G. BESENBRUCH, K. MCCORKLE,* \\ J. NORMAN, and R. SHARP
}

This is a preprint of a paper to be presented at the 20th National Convention, joint AIChE-IMIO meeting in Acapulco, Mexico, Octoher 15-17, 1980 and to be submitted in part to the International Journal of Hydrogen Energy.

Work supported in part by the Department of Energy Contract DE-AC02-80ET26225, Gas Research Institute Contracts 5014323-0122 and 5014323-0258, and General Atomic Company.

"New Mexico State University, Department of Chemical Engineering, Las Cruses, New Mexico

GENERAL ATOMIC PROJECTS 3332, 2252, and 2306 JULY 1980

\section{GENERAL ATOMIC COMPANY}




\section{ABSTRACT}

Portions of a bench-scale model of a sulfur-iodine thermochemical water-splitting cycle have been operated at General Atomic Company as part of a comprehensive program to demonstrate the technology for hydrogen production from nonfossil sources. The hydrogen program is funded by the U.S. Department of Energy, the Gas Research Institute, and General Atomic Company. The bench-scale model consists of three subunits which can be operated separately or together and is capable of producing as much as 4 std liters/min $\left(6.7 \times 10^{-5} \mathrm{~m}^{3} / \mathrm{s}\right.$ at standard conditions) of gaseous hydrogen. One subunit (main solution reaction) reacts liquid water, liquid iodine $\left(\mathrm{I}_{2}\right)$ and gaseous sulfur dioxide $\left(\mathrm{SO}_{2}\right)$ to form two separable liquid phases: 50 wt $\%$ sulfuric acid $\left(\mathrm{H}_{2} \mathrm{SO}_{4}\right)$ and a solution of iodine in hydriodic acid $\left(\mathrm{HI}_{\mathrm{x}}\right)$. Another subunit $\left(\mathrm{H}_{2} \mathrm{SO}_{4}\right.$ concentration and decomposition) concentrates the $\mathrm{H}_{2} \mathrm{SO}_{4}$ phase to the azeotropic composition, then decomposes it at high temperature over a catalyst to form gaseous $\mathrm{SO}_{2}$ and oxygen. The third subunit ( $H I$ separation and decomposition) separates the $\mathrm{HI}$ from water and $\mathrm{I}_{2}$ by extractive distillation with phosphoric acid $\left(\mathrm{H}_{3} \mathrm{PO}_{4}\right)$ and decomposes the $\mathrm{HI}$ in the vapor phase over a catalyst to form $\mathrm{I}_{2}$ and product hydrogen. This paper presents the results of on-going parametric studies to determine the operating characteristics, performance, and capacity limitations of major components. 


\section{INTRODUCTION}

The recent realization that the earth's fossil fuel resources cannot inexhaustibly supply society's needs has prompted investigating many alternative fuel sources. One alternative fuel source is hydrogen from water splitting. Hydrogen, when combined with solar or nuclear heat sources is a renewable, portable fuel from water, which can be stored as a gas, liquid, or hydride, depending on the application. A hydrogen economy appears to have many benefits, and researchers around the world have recently devoted considerable effort to developing viable processes for the economic largescale production of hydrogen fuel from water. The General Atomic Company (GA) sulfur-iodine process is a thermochemical water-splitting approach currently being developed and assessed.

The program to investigate thermochemical water splitting using the high-temperature gas-cooled reactor (HTGR) as a heat source has been underway at GA since October 1972. Current program participants are the Gas Research Institute (GRI), which carries on the sponsorship of the American Gas Association (AGA), the U.S. Department of Energy (DOE), and GA. Northeast utilities Service Company and Southern California Edison Company previously participated.

The GA sulfur-iodine cycle was first described in the open literature by Russell (Ref. 1). Reference 2 is a recent overview of the entire program effort. The chemical basis for thermochemical water splitting is rontained in a review paper on catalysis (Ref, 3), and Refs. 4 and 5 survey the chemical studies performed to establish the process direction. Reference 6 gives specific details on the program process engineering. Reference 7 reports on the materials investigation. 
An abbreviated chemical description of the sulfur-iodine cycle is as follows:

$$
\begin{aligned}
& 2 \mathrm{H}_{2} \mathrm{O}+\mathrm{SO}_{2}+\mathrm{XI}_{2}+\mathrm{H}_{2} \mathrm{SO}_{4}+2 \mathrm{HI} x \quad 95^{\circ} \mathrm{C} \\
& 2 \mathrm{HI}_{\mathrm{x}}+\mathrm{XI}_{2}+\mathrm{H}_{2} \quad 120^{\circ} \mathrm{C} \\
& \mathrm{H}_{2} \mathrm{SO}_{4} \rightarrow \mathrm{H}_{2} \mathrm{O}+\mathrm{SO}_{2}+1 / 2 \mathrm{O}_{2} \quad 870^{\circ} \mathrm{C}
\end{aligned}
$$

The $\mathrm{HI}_{\mathrm{x}}$ represents the mixture of several polyiodides formed in the main solution reaction (Eq. 1). The $\mathrm{H}_{2} \mathrm{SO}_{4}$ and $\mathrm{HI}_{x}$ are separated by gravity, since the acid solutions are almost completely immiscible. The upper phase contains almost all of the $\mathrm{H}_{2} \mathrm{SO}_{4}$, and the lower phase contains most of the $H_{X}$. However, several process engineering steps are needed to perform the reactions described above.

The Fig. I block diagram shows the links between these transformations. GA process engineering efforts estimate the obtainable energy efficiency, guide further chemical investigations, and help develop the flowsheet material and energy balances for realistic cost estimates on specific equipment designs. Presently, overall cycle thermal efficiency for the GA process, as determined from the flowsheets, is estimated at $47 \%$. This paper discusses the status of the bench-scale. testing of the GA sulfuriodine cycle. Prior to these efforts, the process was demonstrated in the recycle mode in a closed loop cycle demonstrator (Ref. 8). 


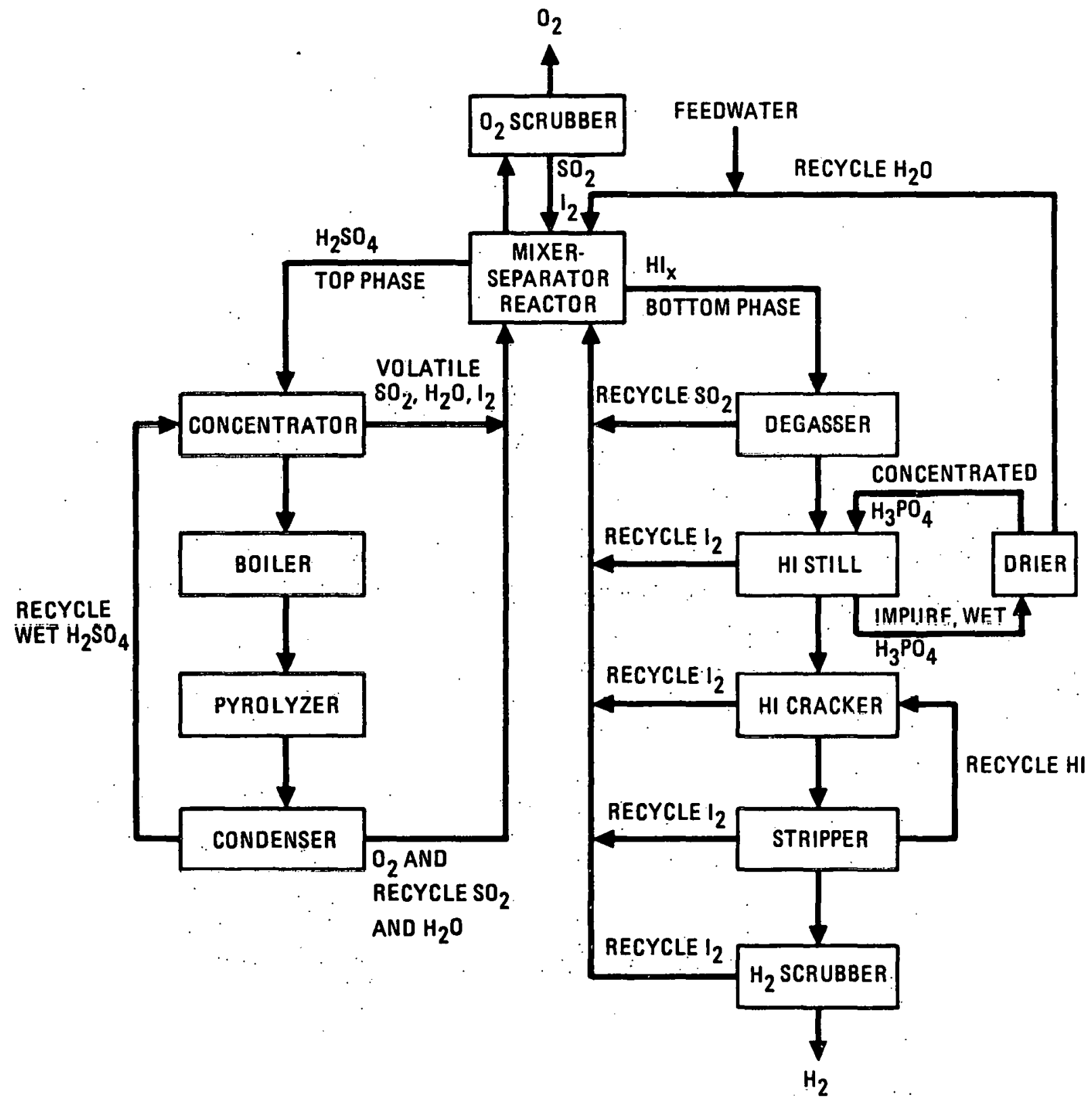

Fig: 1. Sulfur-iodine cycle process model 


\section{DESCRIPTION OF THE GA BENCH-SCALE TESTING UNIT}

In 1977, under DOE contract, GA started the design and construction of a bench-scale unit to perform the sulfur-iodine thermochemical water-splitting cycle as one continuous operation. Except for water fed in and hydrogen and oxygen taken out as products, all materials are internally recycled. The purpose of bench-scale work is generally to study the actual processing steps and their interactions by conducting key continuous flow reactions and separation steps previously done by batch. Bench-scale investigations also report on fluid handling, key operation behavior, and the effects of incomplete physical separations and possible side reactions. In the later study stages, the three bench-scale subunits will be integrated and operated as one unit.

In bench-scale testing, no attempt is made to prove the cycle energy efficiency. The energy efficiency is estimated in the separate conceptual flowsheeting effort. However, the bench-scale components selected can potentially perform efficiently on a large scale. For instance, a flow reactor, rather than a stirred vessel, has been selected for the main solution reactions. Also, the bench-scale is currently not aimed at proving con-: struction materials. Wherever possible, materials, such as inert plastics and glass, are used. However, some specific metals found in the materials screening tests will be added later. All hardware is mounted on Unistrut and Flexframe supports.

For these investigations, the process is divided into three subunits. After these subunits have been proven to operate satisfactorily alone, they can be linked together. The design goal of the bench-scale system is a $\mathrm{H}_{2}$ production rate of $\sim 41$ iters/min $\left(6.7 \times 10^{-5} \mathrm{~m}^{3} / \mathrm{s}\right)$ at standard conditions. The main features of the three subunits are briefly described below. References 9 and 10 give more detailed information on the bench-scale design. 
2.1. SUBUNIT I, $\mathrm{HI}_{-} \mathrm{H}_{2} \mathrm{SO}_{4}$ PRODUCTION AND SEPARATION

The main solution reaction is carried out in this subunit. $\mathrm{I}_{2}, \mathrm{H}_{2} \mathrm{O}$, and $\mathrm{SO}_{2}$ are injected in a cocurrent reactor where the two acid phases are formed. The products are then passed into a gas separator, where excess $\mathrm{SO}_{2}$ is removed for recycle, and eventually into a liquid-liquid separator, where the two phases are separated and collected. Figure 2 is the simplified bench-scale flowsheet for Subunit I.

The main solution reaction (Eq. 1) is carried out at $\leq 250 \mathrm{kPa}$ and at a temperature slightly above the melting point of $\mathrm{I}_{2}$. The reactants $\mathrm{SO}_{2}$ and $\mathrm{H}_{2} \mathrm{O}$ are metered with flow control valves and their flowrate is measured using conventional rotameters. The reactant $I_{2}$ is melted and delivered as a liquid. $I_{2}$ is metered using a Teflon flow control valve, and the flowrate is measured by observing the weight loss of the iodine charge with a load cell attached to the $I_{2}$ vessel.

The main solution reactor was designed to provide adequate reactant mixing and residence time in controlled temperature conditions. The reactor consists of an internal finned tube, which alters fluid flow directions a number of times. This flow is driven by an excess gaseous $\mathrm{SO}_{2}$ flow. The liquid residence time is long compared to the gas residence time (i.e., many seconds compared to fractions of a second). The reactants are supplied to the reactor by a train injection system, where the $\mathrm{SO}_{2}$ enters at the bottom of the train and both $\mathrm{H}_{2} \mathrm{O}$ and $\mathrm{I}_{2}$ ( $1 \mathrm{iq}$ ) are sequentially injected into the flowing $\mathrm{SO}_{2}$. The reactor is jacketed for temperature control. After discharge from the reactor, the reaction mixture flows to a thermostated chamber, which serves as a gas-liquid de-entrainment system. The two liquid phases, which have been de-entrained from the $\mathrm{SO}_{2}$ by gravity, are discharged from the bottom of the separator.

The liquid-liquid separator is very similar in design to the gas-liquid separator and separates the $\mathrm{H}_{2} \mathrm{SO}_{4}\left(\mathrm{sol}^{\prime} n\right)$ phase from the heavier $\mathrm{HI}_{\mathrm{X}}\left(\mathrm{sol}^{\prime} n\right)$ 


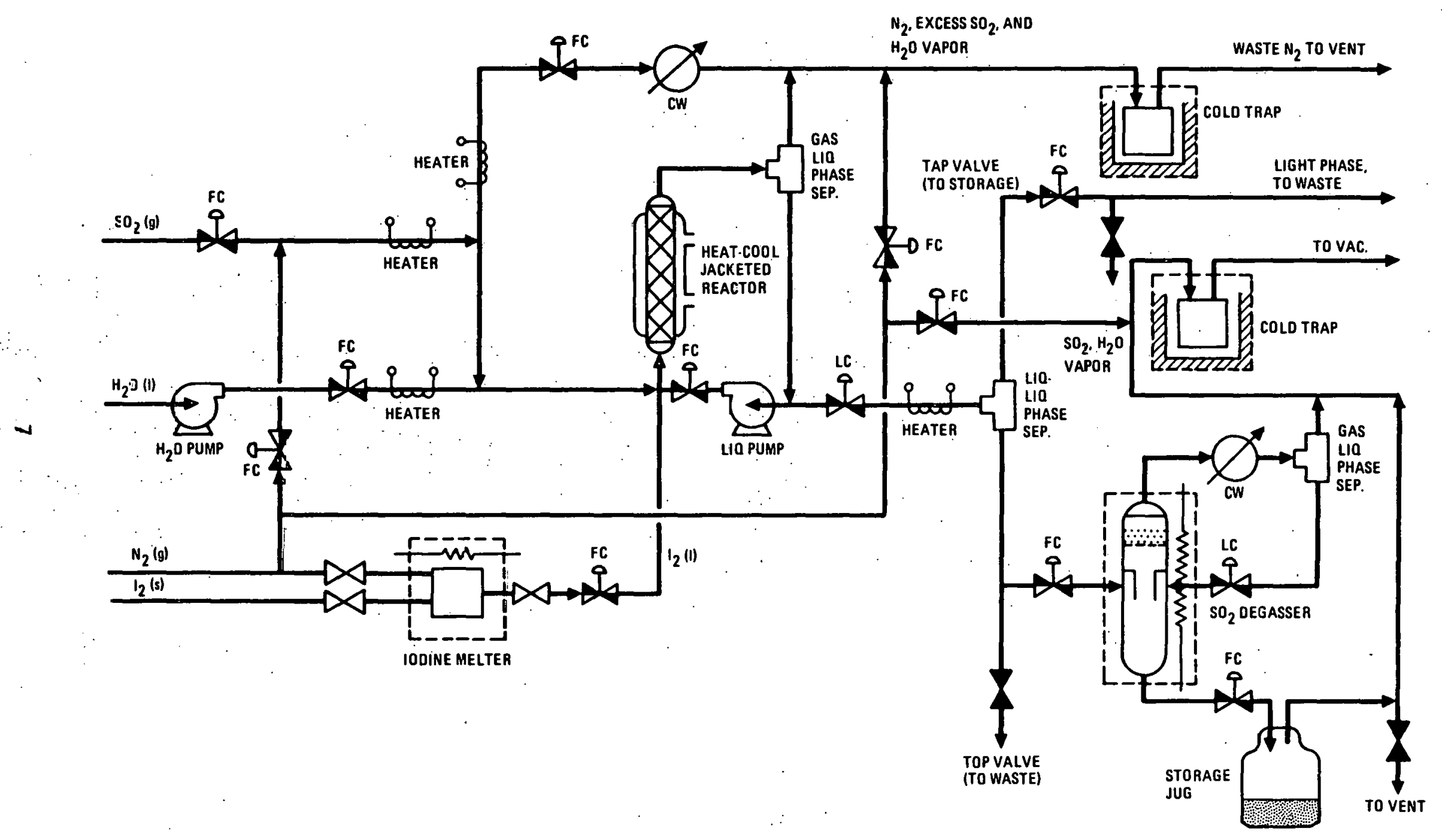

Fig. 2. Simplified bench-scale flowsheet for Subunit I (main solution reaction) 
phase. The $\mathrm{HI}_{x}$ lower phase of the liquid-liquid separator is saturated with unreacted $\mathrm{SO}_{2}$. 'The $\mathrm{SO}_{2}$ must be removed from this phase to avoid forming $\mathrm{H}_{2} \mathrm{O}$ and sulfur by reacting with the product $\mathrm{HI}$ during the various lower phase treatments. A vacuum flask degasser is used to remove the $\mathrm{SO}_{2}$. After degassing, the liquid collects in the bottom of the drum, then is pumped to the next unit. Since $\mathrm{I}_{2}$ and the $\mathrm{HI}_{\mathrm{X}}$ are solids at room temperature (aqueous $\mathrm{HI}_{\mathrm{x}}$ will precipitate $\mathrm{I}_{2}$ as temperature is reduced), forcedair ovens are built around the units.

Figure 3 is a photograph of a portion of Subunit $I$ as installed in the protective fume hood enclosure which houses the complete bench-scale unit.

\subsection{SUBUNIT II, $\mathrm{H}_{2} \mathrm{SO}_{4}$ CONCENTRATION AND DECOMPOSITION}

In this subunit, the $\mathrm{H}_{2} \mathrm{SO}_{4}$ phase from Subunit I is purified, concentrated, and pyrolized at temperatures up to $870^{\circ} \mathrm{C}$. Uncracked $\mathrm{H}_{2} \mathrm{SO}_{4}$ is recycled to the concentration column; then wet $\mathrm{SO}_{2}-\mathrm{O}_{2}$ product can either be passed to a caustic scrub prior to metering and discharging or recycled to Subunit I without removing $\mathrm{O}_{2}$.

Figure 4 shows the simplified flowsheet design for the $\mathrm{H}_{2} \mathrm{SO}_{4}$ concentration and decomposition section.

The feed system for Subunit II provides flow metering of the light phase liquid effluent from Subunit I. The light phase flow from Subunit I is 50 wt $\% \mathrm{H}_{2} \mathrm{SO}_{4}$ aqueous solution at an absolute pressure from ambient to $3.1 \times 10^{5} \mathrm{~Pa}$ and at a temperature from ambient to $115^{\circ} \mathrm{C}$. Variable amounts of $\mathrm{SO}_{2}, \mathrm{HI}$, and $\mathrm{I}_{2}$ on the order of 0.5 to $1.5 \mathrm{wt} \%$ each are dissolved in the solution, with some of the $\mathrm{I}_{2}$ possibly occurring as a solid phase.

Removal of $I_{2}$ from the sulfuric acid is effected by countercurrentily contacting the input liquid against heated water vapor at temperatures and times adequate to vaporize substantially all the $I_{2}$ from the liquid. The heated water vapor is generated from the liquid effluent of the counter- 


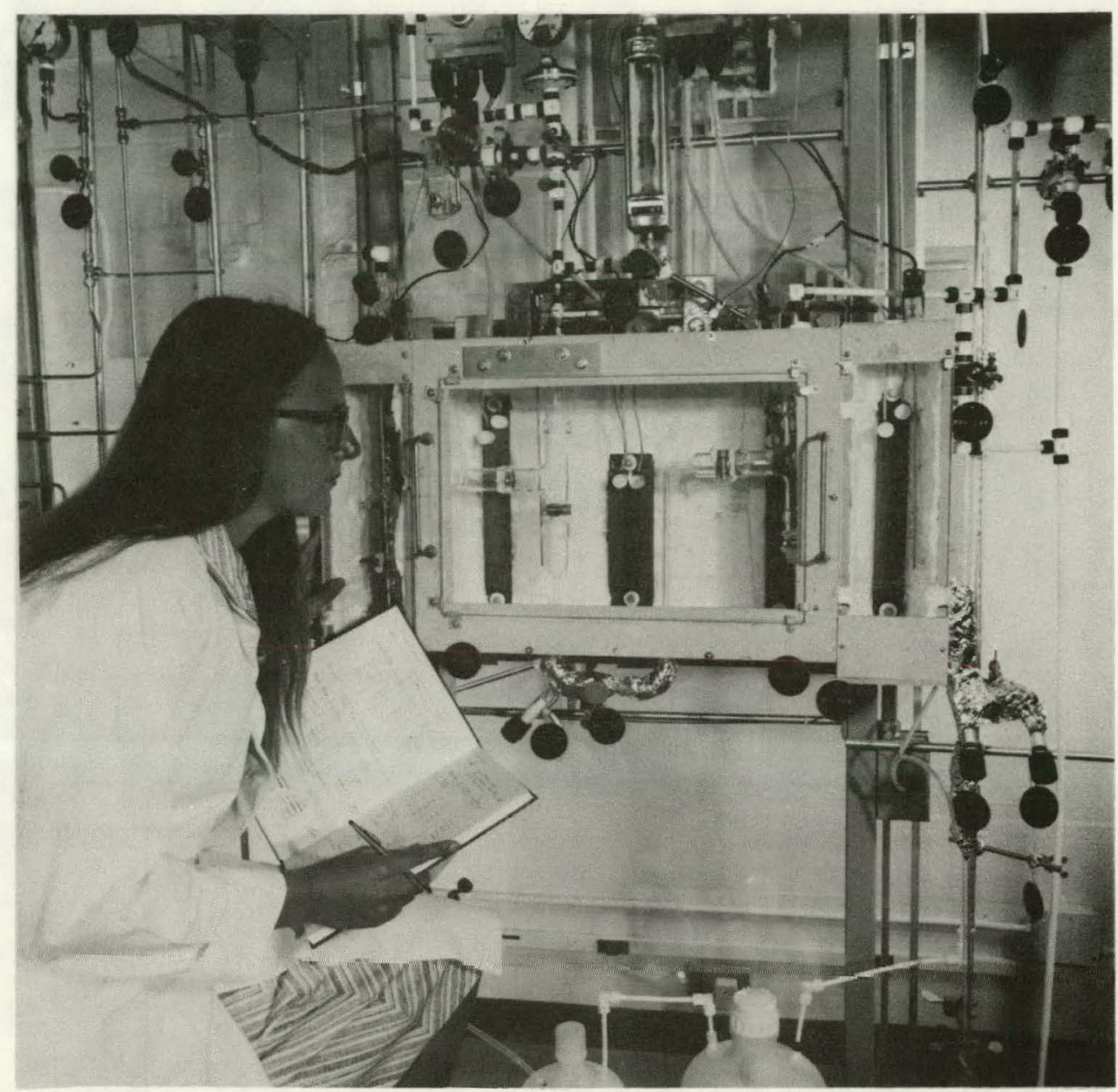

Fig. 3. Photograph of Subunit I as installed in protective fume hood enclosure showing the separator oven and ancillary equipment 


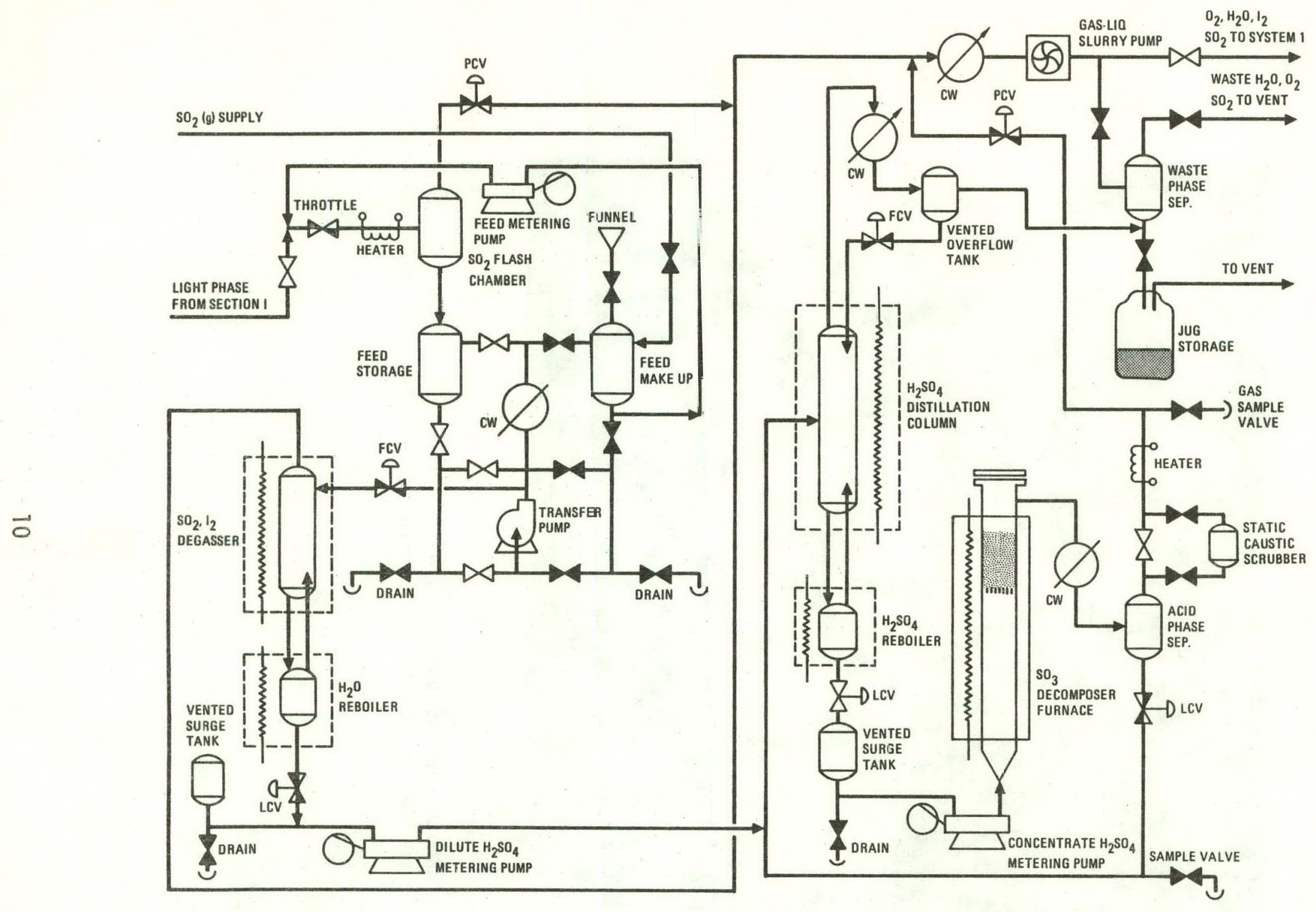

Fig. 4. Simplified bench-scale flowsheet for Subunit II $\left(\mathrm{H}_{2} \mathrm{SO}_{4}-\mathrm{H}_{2} \mathrm{O}\right.$ separation and decomposition) 
current contacting operation After cooling, the acid solution is metered at a controlled flowrate into a fractionation still. The still produces $>96$ wt \% aqueous $\mathrm{H}_{2} \mathrm{SO}_{4}$ and $\mathrm{H}_{2} \mathrm{O}$ vapor substantially free of $\mathrm{H}_{2} \mathrm{SO}_{4}$ in separate streams.

The $\mathrm{H}_{2} \mathrm{SO}_{4}$ decomposition system cools the $>96$ wt $\% \mathrm{H}_{2} \mathrm{SO}_{4}$ effluent of the $\mathrm{H}_{2} \mathrm{SO}_{4}$ concentration system from its normal boiling point to $42^{\circ} \mathrm{C}$. After cooling, the acid is metered at a controlled flowrate into a vertical-tube decomposition chamber, where vaporization of the liquid takes place; then catalytic decomposition of the vapor occurs to within $98 \%$ of equilibrium decomposition. The system provides nominally isothermal decomposition temperatures from $530^{\circ}$ to $1030^{\circ} \mathrm{C}$ at ambient pressure for varying catalyst bed volumes having empty tube nominal slug flow contact times of $<10 \mathrm{~s}$.

The offgas system collects gas from the $\mathrm{SO}_{2}$ removal step, the $\mathrm{HI}-\mathrm{I}_{2}$ removal system, and the $\mathrm{H}_{2} \mathrm{SO}_{4}$ decomposition system through control valves which permit regulating the pressure differential between the offgas system and the other subsections of the overall unit. The system can discharge to the Subunit I feed inlet $\mathrm{SO}_{2}$ stream or to a gaseous waste vent.

For the gaseous effluent of the $\mathrm{H}_{2} \mathrm{SO}_{4}$ decomposition system, the offgas system removes substantially all $\mathrm{SO}_{2}$ from the $\mathrm{O}_{2}$ in a form amenable to subsequent quantitative chemical analysis, and it meters the flow of the $\mathrm{SO}_{2}$ free gaseous effluent or the whole gaseous effluent of the $\mathrm{H}_{2} \mathrm{SO}_{4}$ decomposition system when the $\mathrm{SO}_{2}$ removal capability is bypassed.

Figures $5 a$ and $5 b$ are selected photographs of the Subunit II equipment installed in the protective fume hood.

\subsection{SUBUNIT III, HI SEPARATION AND DECOMPOSITION}

Mainly, this subunit separates HI from the lower phase product of the main solution reaction (containing $\mathrm{HI}, \mathrm{I}_{2}$, and $\mathrm{H}_{2} \mathrm{O}$ ) by treating with concentrated $\mathrm{H}_{3} \mathrm{PO}_{4}$. The $\mathrm{HI}$ is then catalytically decomposed as a gas at moderate 


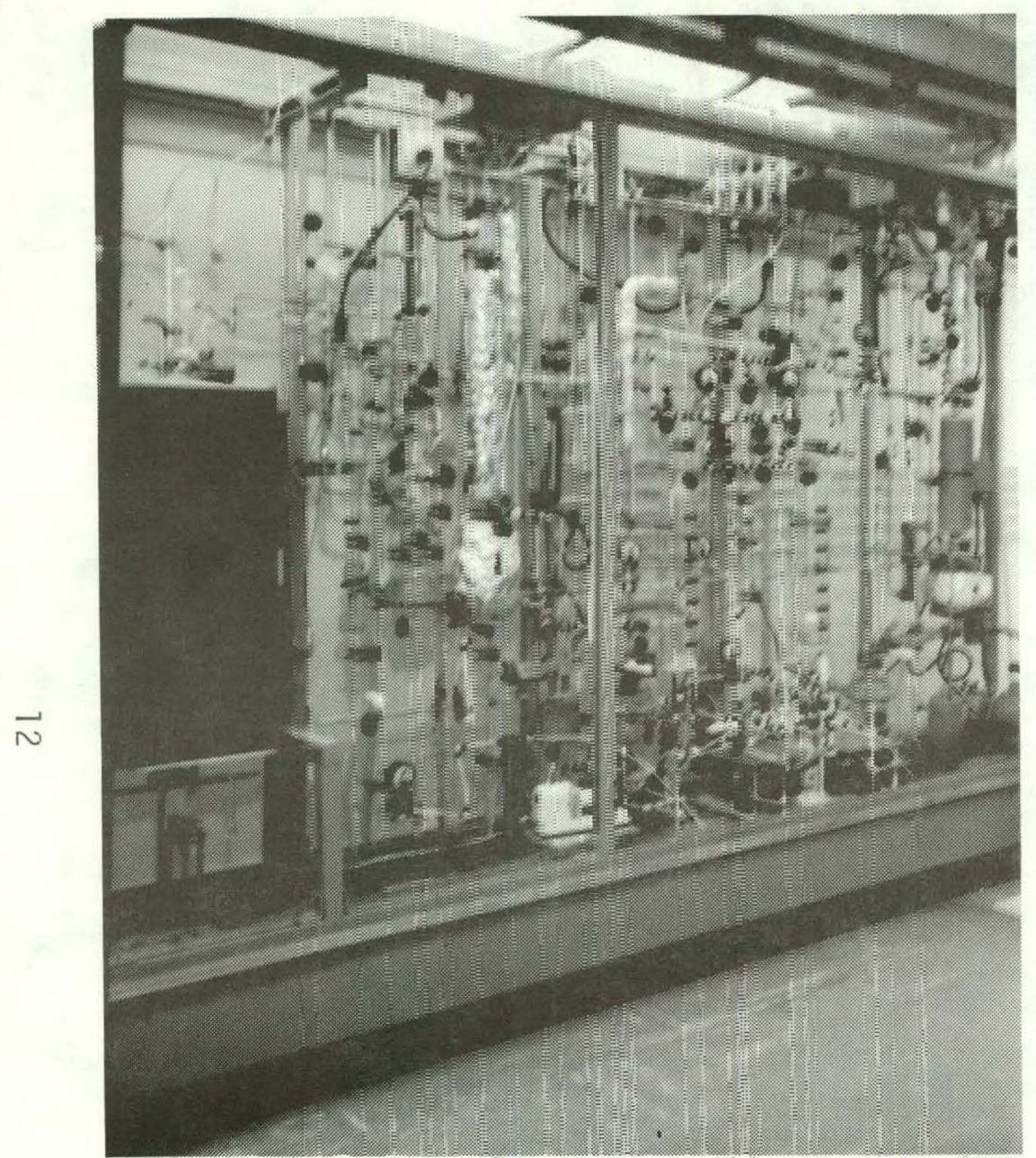

(a)

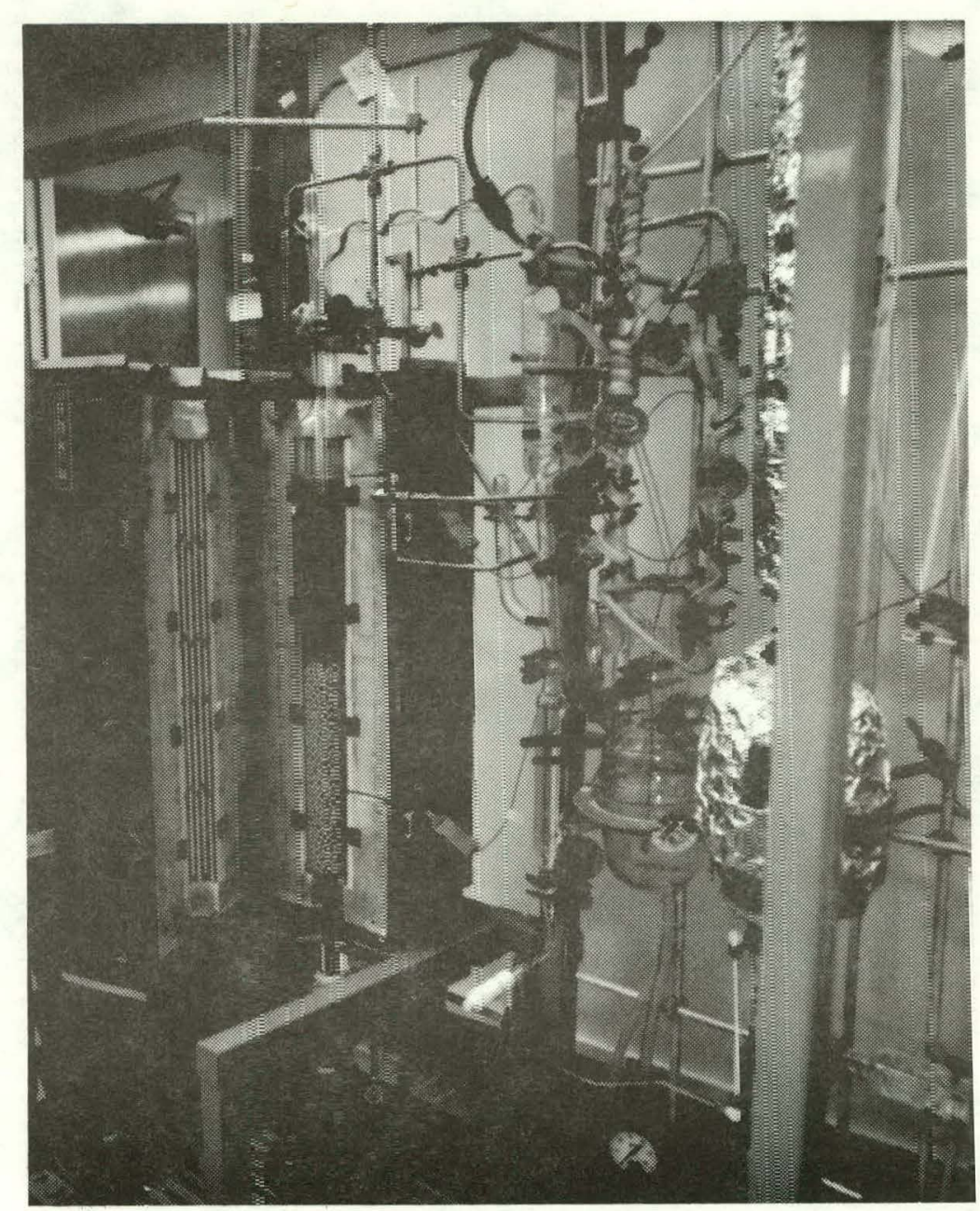

(b)

Fig. 5. Bench-scale Subunit II: (a) overview, (b) $\mathrm{SO}_{3}$ decomosser with catalyst in place 
temperature. Figure 6 shows the flowsheet for Subunit III. The following paragraphs give the basic functions of the principle equipment items.

The feed system provides metered flow of heavy phase liquid effluent from Subunit I at $600 \mathrm{~Pa}$ to an ambient discharge pressure. The heavy phase from Subunit I has a mole ratio composition of $\mathrm{HI} / 3.8 \mathrm{I}_{2} / 5.5 \mathrm{H}_{2} \mathrm{O} / 0.01 \mathrm{H}_{2} \mathrm{SO}_{4}$ from ambient temperature to $97^{\circ} \mathrm{C}$. The nominal $\mathrm{H}_{2} \mathrm{SO}_{4}$ content of actual heavy phase represents a mixture of sulfur species not yet completely defined but which is predominately $\mathrm{H}_{2} \mathrm{SO}_{4}$.

The $I_{2}$ separation system receives heavy phase from the feed system and separates the $\mathrm{I}_{2}$ as liquid from the heavy phase by countercurrent contact with $100 \% \mathrm{H}_{3} \mathrm{PO}_{4}$ at a rate sufficient to substantially remove all water from the liquid $\mathrm{I}_{2}$ that is separated from the heavy phase. The system water scrubs substantially all entrained $\mathrm{H}_{3} \mathrm{PO}_{4}$ from the $\mathrm{I}_{2}$ before the $\mathrm{I}_{2}$ liquid leaves the $\mathrm{I}_{2}$ separation system. Scrubbing operation conditions are maintained such that both the water and the iodine are liquids. The raffinate of the water scrub operation is introduced into the $\mathrm{H}_{3} \mathrm{PO}_{4}-\mathrm{HI}-\mathrm{H}_{2} \mathrm{O}$ phase of the $I_{2}$ separation operation, and the combined flow is conducted to the feed subsystem of the HI distillation step.

The HI distillation column accepts $\mathrm{H}_{3} \mathrm{PO}_{4}-\mathrm{HI}-\mathrm{H}_{2} \mathrm{O}$ solution from the $I_{2}$ separation step and provides a gaseous effluent of $\mathrm{HI}$ vapor that is substantially free of water vapor. The HI is accompanied by a variable amount of $I_{2}$ vapor flow. The $I_{2}$ vapor flow is still undefined but is certainly substantially smaller than the flowrate of the combined $\mathrm{HI}-\mathrm{I}_{2}$ effluent from the $\mathrm{HI}$ distillation step. Approximately 85 wt $\% \mathrm{H}_{3} \mathrm{PO}_{4}$ effluent, which is substantially free of $\mathrm{HI}$ and at a temperature less than $77^{\circ} \mathrm{C}$, leaves the HI distillation step and is conducted by gravity to the $\mathrm{H}_{3} \mathrm{PO}_{4}$ concentration step. $\mathrm{HI}-\mathrm{H}_{2} \mathrm{O}$ is separated by extractive distillation, using $\mathrm{H}_{3} \mathrm{PO}_{4}$ as the extraction agent. Distillation overhead reflux is $100 \% \mathrm{H}_{3} \mathrm{PO}_{4}$.

In the $\mathrm{H}_{3} \mathrm{PO}_{4}$ concentration column, the 85 wt $\% \mathrm{H}_{3} \mathrm{PO}_{4}$ effluent of the HI distillation step is heated to sufficient temperature, $\angle 222^{\circ} \mathrm{C}$, 


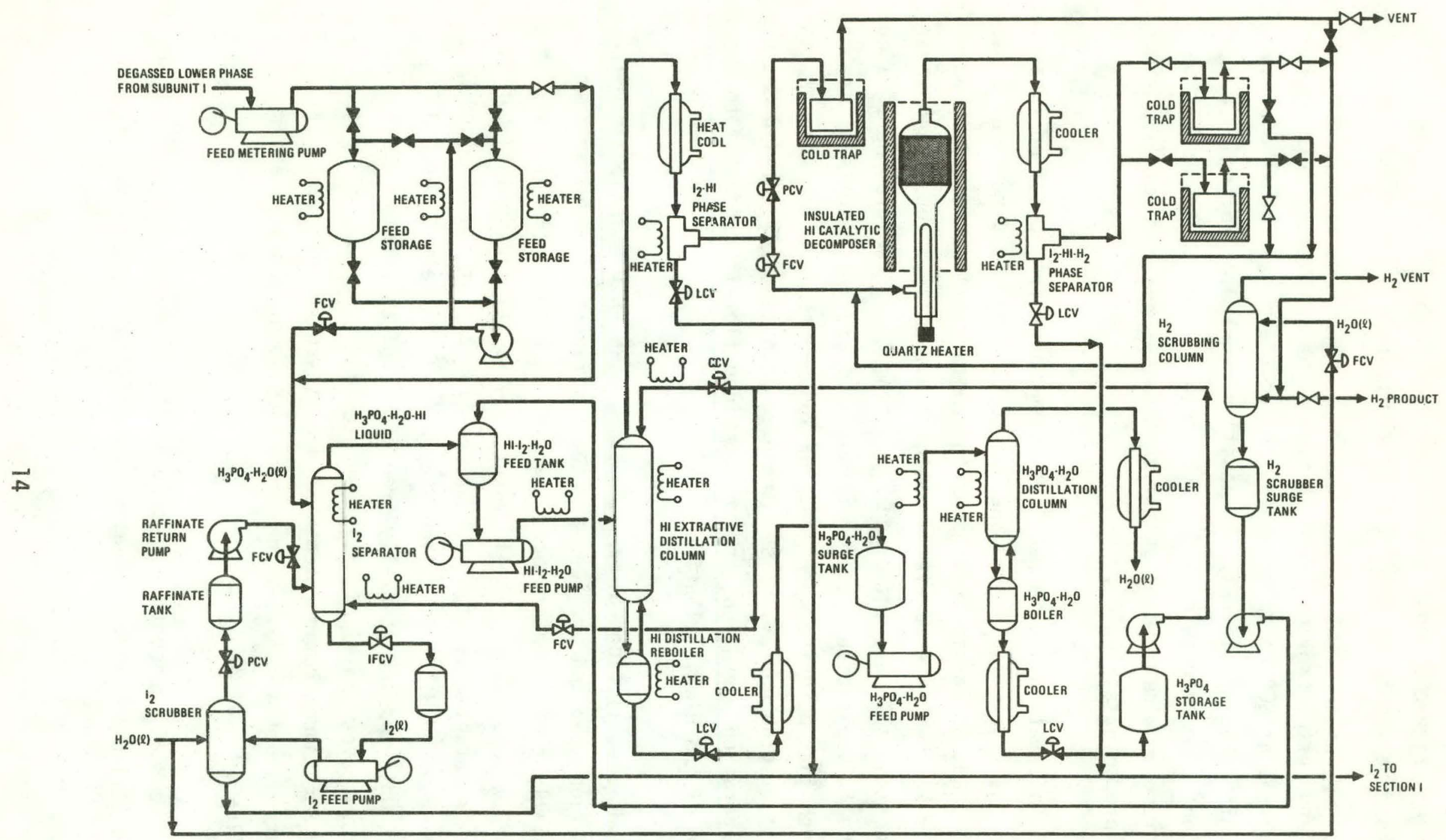

Fig. 6. Simplified bench-scale flowsheet for Subunit III (HI concentration and decomposition) 
to substantially remove all water vapor from the $\mathrm{H}_{3} \mathrm{PO}_{4}$. The water vapor is then discarded, and $100 \% \mathrm{H}_{3} \mathrm{PO}_{4}$ is recycled to the $\mathrm{I}_{2}$ separation system and to the $\mathrm{HI}$ distillation step at the metered rates specified in the design criteria for those subsections of bench-scale Subunit III. Effluent water vapor is condensed before being discarded to the waste $\mathrm{H}_{2} \mathrm{O}$ collection vessel.

The $\mathrm{HI}$ and $\mathrm{I}_{2}$ vapor effluent from the $\mathrm{HI}$ distillation step is cooled in a condenser to a temperature slightly exceeding the melting point of iodine, and condensed iodine separated from the residual vapor before the vapor is metered and sent to the vertical tubular heated chamber. Thermal decomposition of the $\mathrm{HI}$ vapor occurs in the heated chamber at a controlled temperature in the range $177^{\circ}$ to $925^{\circ} \mathrm{C}$ at substantially ambient atmospheric pressure. The controlled temperature volume for $\mathrm{HI}$ decomposition is $\sim 4 \times 10^{-3} \mathrm{~m}^{3}$, including catalyst volume, if any. The present integrated bench scale system employs: gaseous HI decomposition. This will be replaced by a liquid hydrogen iodide process step which is now being tested as a separate bench-scale unit. This latter unit is discussed in this paper under the heading "Future Work."

The HI decomposition gaseous products are first cooled to a temperature slightly above the melting point of iodine $\left(114^{\circ} \mathrm{C}\right)$, and condensed iodine is separated from the residual gas vapor. The residual gas vapor from the $\mathrm{I}_{2}$ condensation is then chilled with liquid nitrogen or dry ice to a sufficiently low temperature to remove substantially all condensable vapors from the $\mathrm{H}_{2}$ product gas. Provision also is made to revaporize the $\mathrm{HI}$ condensed at liquid nitrogen or dry ice temperature for recycle at metered rates to the HI decomposition step.

The $\mathrm{H}_{2}$ purification step provides countercurrent scrubbing with water to remove low concentrations of $\mathrm{HI}$ from the effluent $\mathrm{H}_{2}$ of the $\mathrm{HI}$ recycle system.

Figures $7 \mathrm{a}$ and $7 \mathrm{~b}$ are photographs of Subunit III as installed for operation. 


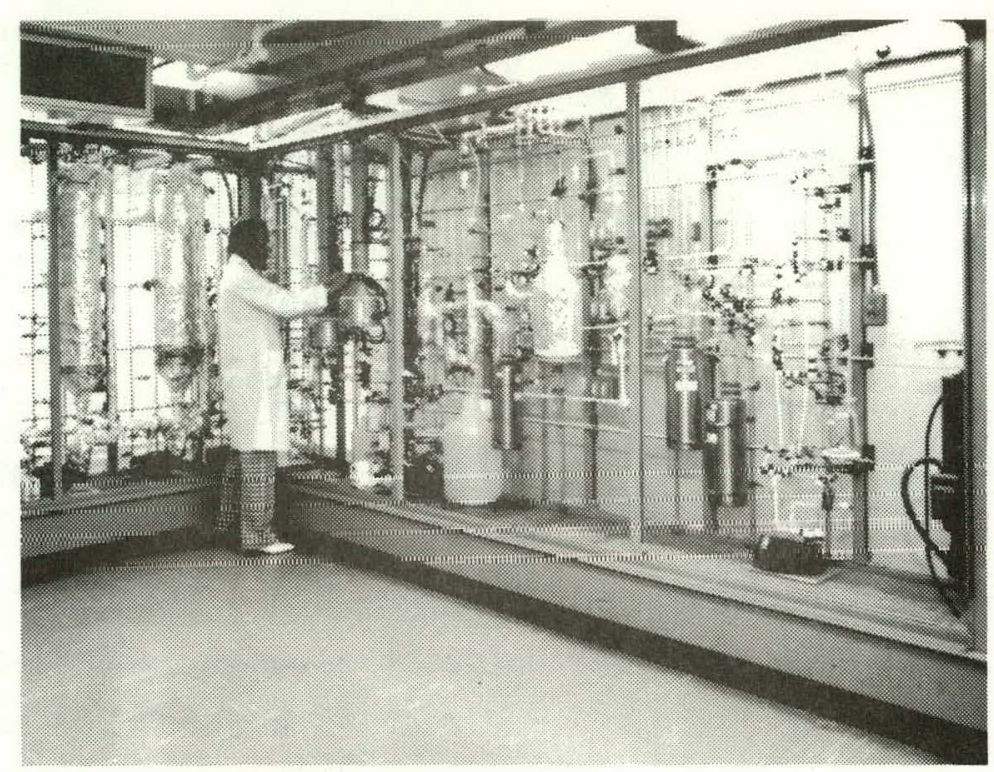

(a)

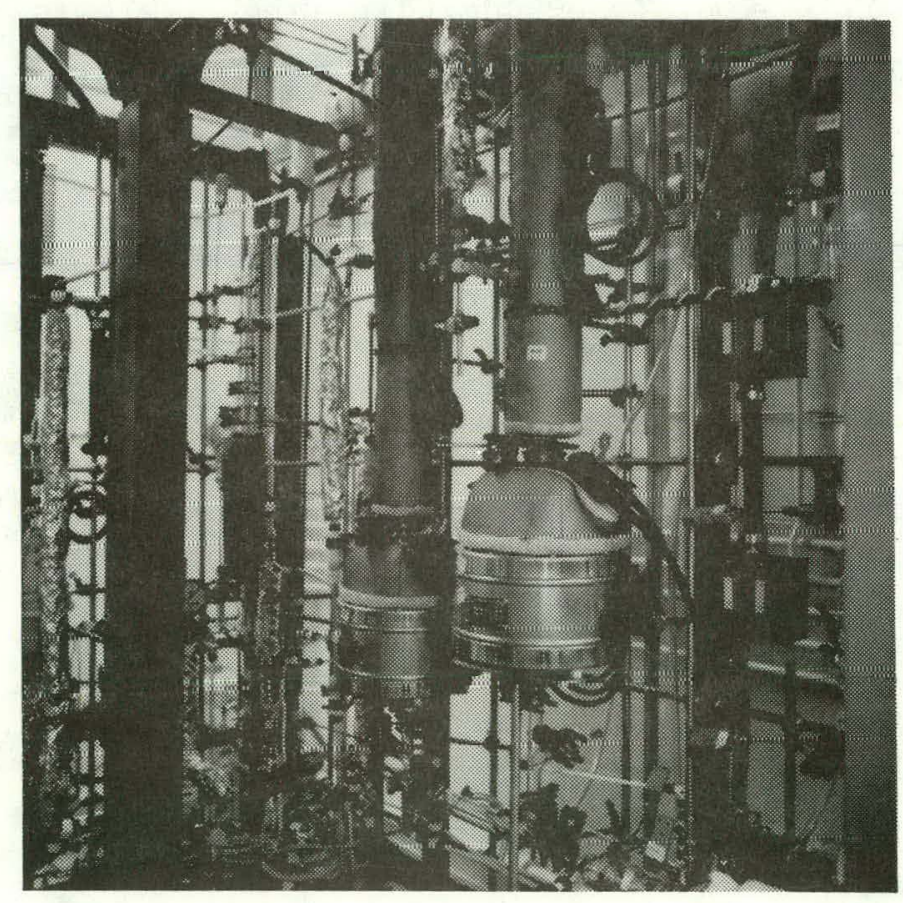

(b)

Fig. 7. Bench-scale Subunit III: (a) overview, (b) HI extractive distillation column and $\mathrm{H}_{3} \mathrm{PO}_{4}-\mathrm{H}_{2} \mathrm{O}$ distillation column 


\section{PRELIMINARY RESULTS OF BENCH-SCALE TESTING}

At this writing, preliminary tests on Subunits I and II have been conducted; Subunit III has not yet been tested. The results of the available tests are described below.

\subsection{RESULTS OF SUBUNIT I PRELIMINARY TESTS}

\subsubsection{Cold Testing of the Engineering Characteristics of Subunit I}

After assuring integrity by pressure leak testing, flow characteristics of the constructed unit were qualitatively determined. In some preliminary cold flow tests, $\mathrm{CH}_{3}-\mathrm{CCl}_{3}$ with a little dissolved $\mathrm{I}_{2}$ was used to simulate molten $\mathrm{I}_{2}$, and $\mathrm{N}_{2}$. was used in place of $\mathrm{SO}_{2}$. During the tests, the flow control, reactor flow, and separator characteristics were all observed. After these tests, the reactor fin system was changed to provide better mixing properties. Also determined was that the reactor operation depends on continuous visual monitoring and manual flow adjustment unless the system control is automated. Steadystate operation of the reaction under present circumstances is best assured by achieving and maintaining stable levels in the gas-liquid and liquid-liquid interfaces in the two separators. Level stabllization coupled with constant inlet flow of $\mathrm{H}_{2} \mathrm{O}$ and $\mathrm{I}_{2}$ allows attainment of steady state by manual operation. Also noted was that a considerable excess of $\mathrm{SO}_{2}$ was needed to drive the liquids through the reactor fin system.

\subsubsection{Hot Testing of the Ovens in Subunit II}

The thermal characteristics of the ovens built around the gas-liquid and liquid-liquid phase separators have been tested. The first test revealed the temperature gradients in the ovens to be too large. To 
solve this problem, forced air circulation and additional insulation were added to the ovens. In addition, a similarly thermally insulated chamber for the $\mathrm{I}_{2}$ melt vessel was replaced by a heating mantle since keeping the $I_{2}$ melted was difficult using: the external heating cools associated with the first design. In the new configuration, $\sim 9 \mathrm{~kg}$ of fresh $\mathrm{I}_{2}$ crystals (bulk density $\sim 2.2 \mathrm{~g} / \mathrm{m}^{3}$ ) in a glass vessel is initially melted in 30 min with a l-kW external electrical heating mantle. Resolidified iodine with a higher bulk density takes somewhat longer to melt.

\subsubsection{Initial Data Obtained from Operation of Subunit I}

Several experiments yielding useful data have been conducted with Subunit I. Initially, two tests were conducted with relatively. low weight ratios of $\mathrm{I}_{2}$ to $\mathrm{H}_{2} \mathrm{O}$ of $\times 2.5$. Analysis of the light phase after degassing indicated $\mathrm{H}_{2} \mathrm{SO}_{4}$ concentrations of between 42 and 44 wt \%, whereas the design concentration is $50 \mathrm{wt} \%$. Another test was then run employing a weight ratio of $\mathrm{I}_{2}$ to $\mathrm{H}_{2} \mathrm{O}$ of 5.3 and the concentration of the $\mathrm{H}_{2} \mathrm{SO}_{4}$ product phase increased to $49 \mathrm{wt} \%$, which is close to design value. The design weight ratio of $\mathrm{I}_{2}$ to $\mathrm{H}_{2} \mathrm{O}$ is 27.0 .

These experiments have verified the concept of a cocurrent reactor for the main solution reaction and, in general, the operability of the components in Subunit I. In addition, the experiments indicate that flowsheet design conditions can be met without great difficulty.

\subsection{RESULTS OF SUBUNIT II PRELIMINARY TESTS}

\subsubsection{Cold Testing of the Engineering Characteristics of Subunit II}

Equipment shakedown, including leak testing, instrument calibration, and verification of functional operability with water and inert gas, were conducted on this subunit. As with Subunit I, no fundamental process design problems were discovered during shakedown. Severai minor equipment design problems, such as pump air lock and inoperable flow-indicators, were uncovered. The system was subsequentiy modified to incorporate the required changes. 


\subsubsection{Initial Data Obtained from Operation of Subunit II}

At this writing, several experiments using synthetic feeds were conducted in Subunit II to check operation of the various components under actual conditions and to gather data needed for scale-up design. Several very simple component changes were made to insure efficient operation. In addition, the centrifugal pumps had to be replaced with inert gas pressurization to initiate system flows. Through what appears to be a nucleation controlled process, the centrifugal pumps caused precipitation of $I_{2}$ crystals and possibly sulfur from the fluids, with concomitant problems of partial flow blockage and feed concentration changes. This problem occurred when the synthetic feed solutions were stored a relatively long time ( $1 \mathrm{~h}$ or more). Apparently, storage for these lengths of time results in a supersaturation of $\mathrm{I}_{2}$ and sulfur due to slight back reaction of the $\mathrm{H}_{2} \mathrm{SO}_{4}$ and $\mathrm{HI}$ in solution. This supersaturation should not be a problem in any large-scale continuous flow system, where the chemical storage times would be minimal.

3.2.2.1. Iodine Stripping Experiments. Experiments were carried out in bench-scale Subunit II to establish design parameters for the iodine removal from the upper phase sulfuric acid. Removal of the iodine from the upper phase will reduce potential corrosion problems during final concentration of the acid and allow the use of lower cost system construction materials.

Experiments were carried out in the iodine stripping column of benchscale Subunit II shown in Fig. 8. The iodine stripping column consists of a pyrex tube $(60 \mathrm{~cm}$ long, $3 \mathrm{~cm}$ diam) filled with glass beads ( $3 \mathrm{~mm}$ diam). The column is externally heated and insulated. Sulfuric acid ( $250 \mathrm{wt} \%$ ) containing $\sim 1.2 \% \mathrm{HI}$ and $0.6 \% \mathrm{I}_{2}$ is fed to the top of the heated column. Iodine is removed from the liquid by steam stripping with the water evaporating from the liquid. This changes the $\mathrm{HI} / \mathrm{I}_{2}$ equilibrium, allowing the hydrogen iodide to react with the $\mathrm{H}_{2} \mathrm{SO}_{4}$ to form $\mathrm{I}_{2}, \mathrm{SO}_{2}$, and $\mathrm{H}_{2} \mathrm{O}$ via Eq. 1. The $\mathrm{I}_{2}$ and $\mathrm{SO}_{2}$ so formed are further stripped from the liquid. The experiments were carried out at various temperatures and three 


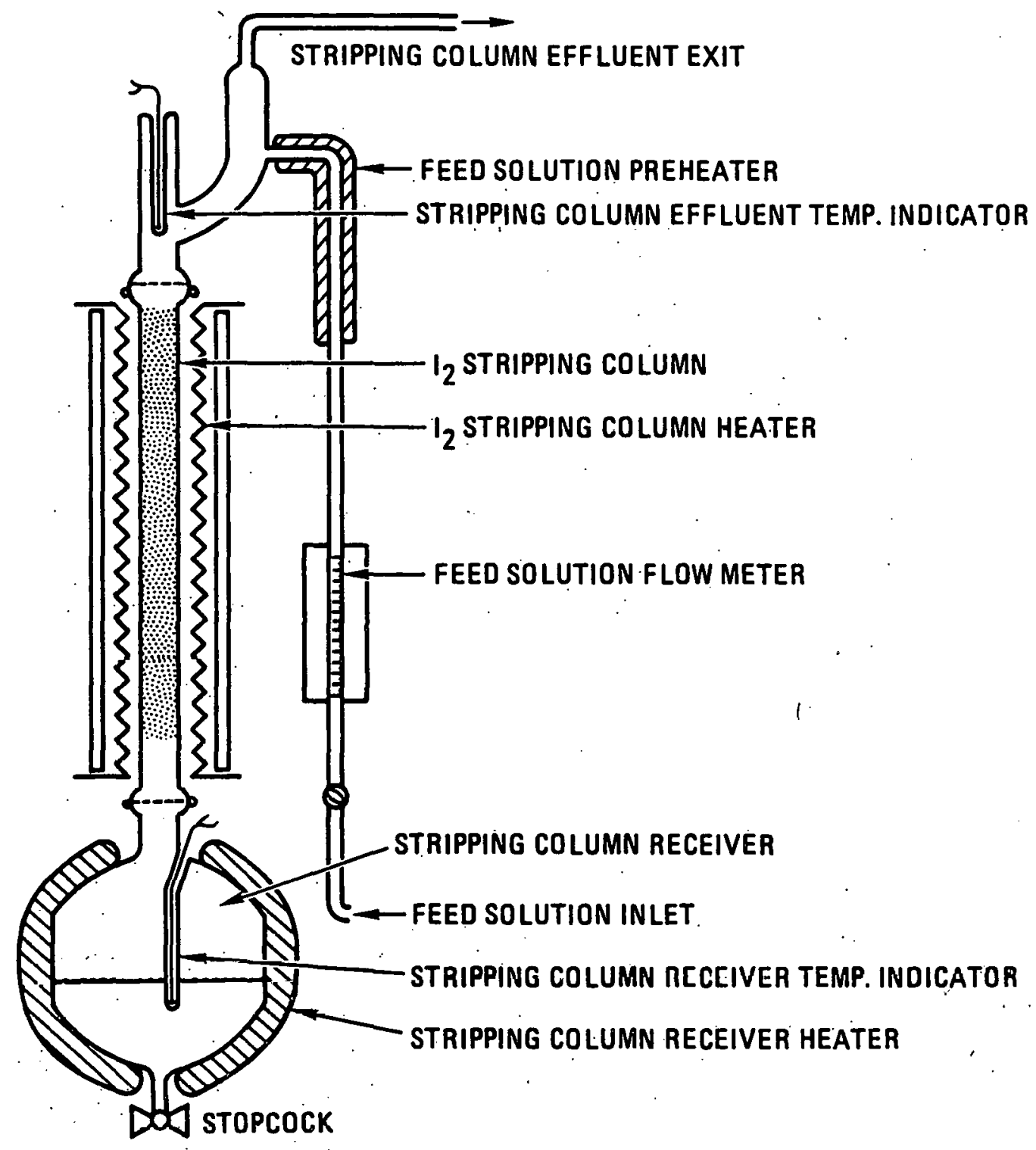

Fig. 8. Schematic of iodine stripping column in use in Subunit II 
different feed flow rates. The results are given in Table 1 and plotted in Fig. 9.

The concentrator temperature was calculated from the known boiling point data (Ref. 11) for sulfuric acid and its measured concentration in the stripping column receiver. Because no thermocouple exists central to the column in this particular design and because inner and outer regions of the column have large temperature differences, this calculation is necessary for the present runs. The acid concentration was obtained by standard laboratory titration methods; the small amounts of $I_{2}$ (both in the form of $I_{2}$ and $H I$ ) were measured by neutron activation analysis.

The results indicate that at flowrates of 10 and $17 \mathrm{~cm}^{3} \mathrm{H}_{2} \mathrm{SO}_{4} /$ min very good stripping of the iodine can be achieved at relatively low temperatures. At a flowrate of $5 \mathrm{~cm}^{3} / \mathrm{min}$, bypass flow apparently occurs in the column, and the results are somewhat erratic. Each of these $\mathrm{I}_{2}$ stripping tests were run for several hours. Very low $\mathrm{I}_{2}$ concentrations were achieved, but presently, exact permissible levels of $I_{2}$ concentrations are not known. Nevertheless, these data will be useful in scale-up design for the process.

When the -79 curve and the -83 curve of Fig. 9 are compared, the concentration of $\mathrm{I}_{2}$ in the effluent increases by a factor of 3.5 when the flowrate is increased by a factor of 1.7, with constant temperature at the bottom of the column. Since the constant temperature is a boiling condition, the column bottom concentration is the same at both flowrates, and the liquid-to-vapor flowrate mole ratio of the column is practically unchanged. With constant feed input composition at the top, the operating vapor equilibrium line behavior on a mole fraction plot should be nearly unchanged. For the observed large shift in the bottom liquid concentration with flowrate, simple interphase diffusion as the dominant mass transfer resistance mechanism is unlikely. The effect of gas flowrate on the height of a transfer unit is, in general, small, as is the effect of liquid flowrate. As an example, see page 236, Ref. 12, for the effect 
TABLE 1

RESULTS OF $I_{2}$ STRIPPING EXPERIMENTS

\begin{tabular}{|c|c|c|c|c|}
\hline Sample No. & $\begin{array}{l}\text { Column } \\
\text { Temperature } \\
\left({ }^{\circ} \mathrm{C}\right)\end{array}$ & $\begin{array}{c}\text { Feed } \\
\text { Flowrate } \\
\left(\mathrm{cm}^{3} / \mathrm{min}\right)\end{array}$ & $\begin{array}{c}\mathrm{H}_{2} \mathrm{SO}_{4} \\
\text { Concentration } \\
\text { (wt \%) }\end{array}$ & $\underset{\substack{\mathrm{I}_{2} \\
\text { Concentration }}}{(\mathrm{a})}$ \\
\hline $3260-90-1750$ & 135 & $5: 0$ & 57.9 & 23.54 \\
\hline $3260-90-1815$ & 141 & $5: 0$ & 60.5 & 15.13 \\
\hline $3260-90-1895$ & 132 & 5.0 & .56 .4 & 15.33 \\
\hline $3260-90-1550$ & $\cdot 138$ & 5.0 & 59.5 & -- \\
\hline $3260-90-1620$ & 140 & 5.0 & 60.0 & 14.86 \\
\hline $3260-90-1303$ & 152 & 5.0 & 65.7 & -- \\
\hline $3260-90-1333$ & 158 & 5.0 & $67 . .5$ & -- \\
\hline $3260-90-1403$ & 148 & $5: 0$ & 64.0 & 2.89 \\
\hline $3260-90-1430$ & 143 & 5.0 & 62.5 & 0.76 \\
\hline $3260-90-1930$ & 197 & 5.0 & 78.9 & 0.99 \\
\hline $3260-90-1053$ & 228 & 5.0 & 93.3 & -- \\
\hline $3260-90-1123$ & 228 & 5.0 & 93.4 & 0.0 \\
\hline $3260-79-1030$ & 148 & 10 & 63.9 & 1.86 \\
\hline $3260-79-1230$ & 141 & 10 & 60.6 & 4.82 \\
\hline $3260-79-1407$ & 133 & 10 & 56.9 & 14.35 \\
\hline $3260-83-1058$ & 160 & 10 & 68.3 & 0.66 \\
\hline $3260-83-1326$ & 164 & 17 & 69.6 & 3.26 \\
\hline $3260-83-1508$ & 185 & 17 & 75.9 & 1.15 \\
\hline $3260-83-1645$ & 150 & 17 & 64.2 & 7.88 \\
\hline
\end{tabular}

${ }^{(a)} \mathrm{I}_{2}$ concentration includes $\mathrm{I}_{2}$ in the form $\mathrm{I}_{2}$ and $\mathrm{HI}$. 


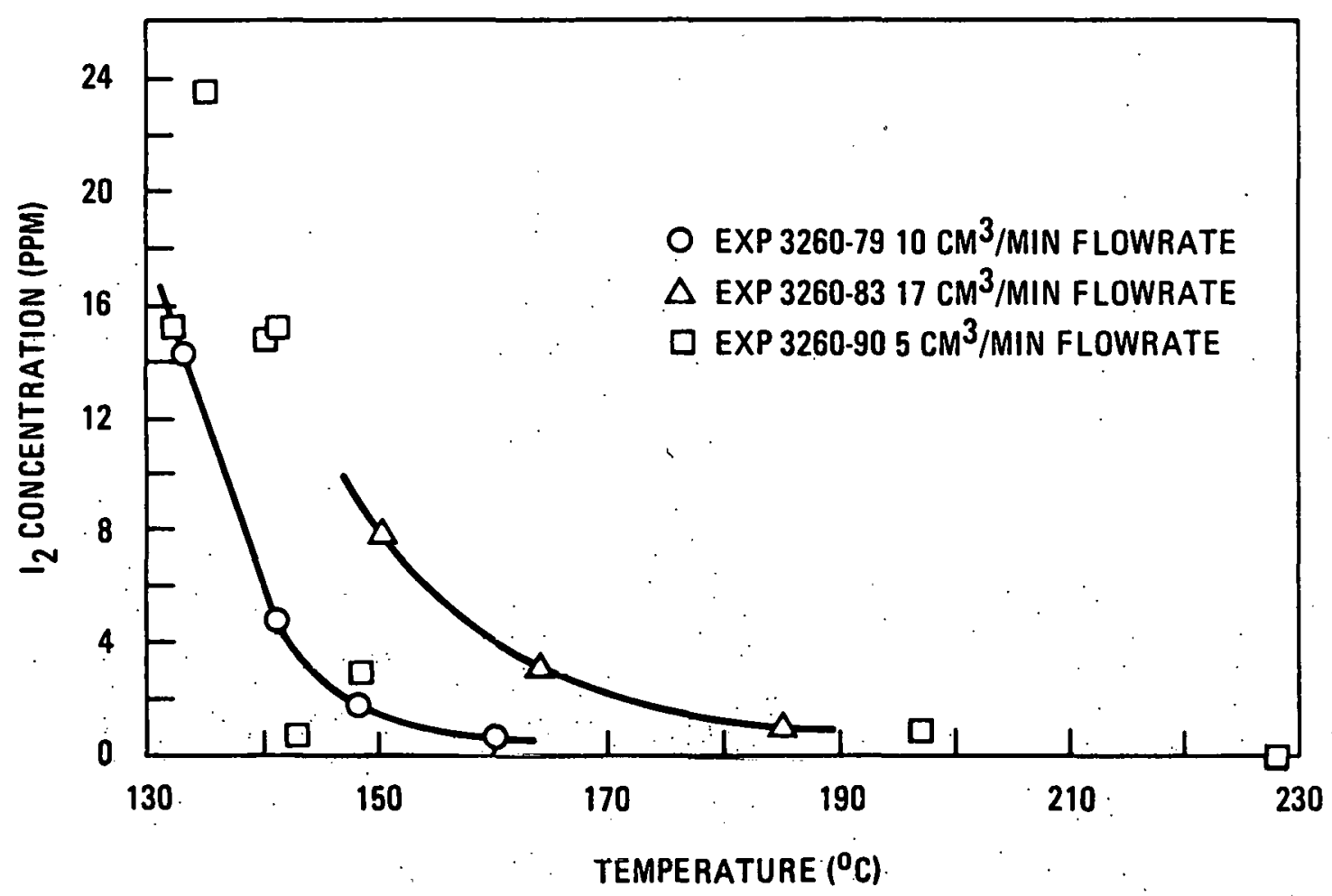

Fig. 9. I 2 concentration versus column temperature for Subunit II for 5, 10 , and $17 \mathrm{~cm}^{3} / \mathrm{min}$ feed flowrates 
of flowrates on desorption of $\mathrm{O}_{2}$ from $\mathrm{H}_{2} \mathrm{O}$.

Probably, the $\mathrm{I}_{2}$ concentration in the liquid effluent is controlled by the rate of reaction between $\mathrm{HI}$ and $\mathrm{H}_{2} \mathrm{SO}_{4}$ to generate free, volatile $I_{2}$. Also, probably, the average residence time of the fluid flowing through the column is an important parameter with respect to this reaction. Further experiments to test the foregoing hypothesis are planned.

3.2.2.2. $\mathrm{H}_{2} \mathrm{SO}_{4}$ Concentration Experiments. The $\mathrm{H}_{2} \mathrm{SO}_{4}$ concentration process provides $>96$ wt $\% \mathrm{H}_{2} \mathrm{SO}_{4}$ to the $\mathrm{SO}_{3}$ decomposer. Since extensive vaporliquid equilibria data already exist for $\mathrm{H}_{2} \mathrm{SO}_{4}-\mathrm{H}_{2} \mathrm{O}$ (e.g. . Ref. 11), the only data taken in these bench-scale studies is practical-operational with respect to accepting the upstream output rate and meeting the downstream input concentration specification.

For a feedrate of $5 \mathrm{~cm}^{3} / \mathrm{min}$ of $60 \mathrm{wt} \% \mathrm{H}_{2} \mathrm{SO}_{4}$ (equivalent to $1 . \mathrm{std}$ liter/min $\mathrm{H}_{2}$ ), the equipment was able to supply $\mathrm{H}_{2} \mathrm{SO}_{4}$ in excess of 96 wt \% without the originally specified glass feed preheater. With an Inconel feed preheater installed, the concentrated $\mathrm{H}_{2} \mathrm{SO}_{4}$ output rate (equivalent to 3 std 1 iters/min $\mathrm{H}_{2}$ ) could be tripled, but the metal contamination of the product, judged qualitatively by color change, was deemed unacceptable. As a practical solution, the required additional heat was supplied via an emersion heater. in the still pot. This arrangement operated satisfactorily for feedrates of $60 \mathrm{wt} \%$ acid equal to 10 $\mathrm{cm}^{3} / \mathrm{min}$. The upper limit of feedrate that the current installation can carry without dropping the output concentration below 96 wt $\% \mathrm{H}_{2} \mathrm{SO}_{4}$ is presently being investigated.

The $\mathrm{H}_{2} \mathrm{SO}_{4}$ output concentration is determined by titration of samples and by literature data from Ref. 11, which relates boiling point to temperature in the still pot. Concentration values obtained by titration measurement typically are $21 \%$ lower than by still pot boiling temperature The discrepancy is fairly constant and may be due to temperature measurement error or to the extremely hygroscopic $\mathrm{H}_{2} \mathrm{SO}_{4}$ diluting by adsorbing atmospheric moisture. Although no special dry box provisions were 
employed with respect to sampling and titration, the discrepancy is small.

\subsubsection{3. $\mathrm{H}_{2} \mathrm{SO}_{4}$ Decomposition Experiments. Experiments evaluated the} decomposing of $\mathrm{H}_{2} \mathrm{SO}_{4}$ into $\mathrm{SO}_{2}, \mathrm{H}_{2} \mathrm{O}$, and $\mathrm{O}_{2}$ and observed any catalyst changes in the bench-scale apparatus. A platinum on zirconia catalyst, $0.3175 \mathrm{~cm}(1 / 8 \mathrm{in}$. diam) right cylinder pellets containing $20.2 \mathrm{wt} \%$ platinum was used at temperatures between $800^{\circ}$ to $900^{\circ} \mathrm{C}$. The gas slugflow residence time in the reactor was between 0.3 to $1 \mathrm{~s}$. Figure 10 shows the gas decomposition results for the four runs obtained thus far. These data points were calculated both by measuring the amount of unreacted $\mathrm{H}_{2} \mathrm{SO}_{4}$ which condensed in the decomposer effluent and the oxygen output flowrate after caustic absorption of the $\mathrm{SO}_{2}$. The two methods agree to within $\pm 5 \%$, with the condensed $\mathrm{H}_{2} \mathrm{SO}_{4}$ analysis being preferred as the more accurate; this latter method is the basis for Fig. 10. Catalyst bed temperature is taken to be the maximum reading of an axial temperature traverse of the bed taken during steady-state operation.

Sulfuric acid flowrates of 3.0 and $5.3 \mathrm{~cm}^{3} / \mathrm{min}$ (equivalent to 1.1 and 2.0 std liters/min $\mathrm{H}_{2}$, respectively) were employed. The experimental results are within $\pm 2 \%$ of the theoretical prediction using the maximum catalyst temperature and the equilibrium composition calculated from the JANAF tables (Ref. 13). The low point at $\sim 875^{\circ} \mathrm{C}$ in Fig. 10 was obtained in a loading of the catalyst bed for which a significant portion of the bed was in the exit region where the temperature had substantially fallen off from the maximum near the axial center of the decomposer. This resulted in a significant back reaction of the decomposition products from the hotter region and thus a low conversion compared to theoretical. This problem was rectified by shortening the catalyst bed and using only the hottest region of the decomposer. The other data points in Fig. 10 were taken using such a configuration.

In the first decomposition run, zirconia pellets without platinum were used to support the catalyst in the hottest zone of the vertical furnace. The zirconia bed support at the boiling interface of the concentrated $\mathrm{H}_{2} \mathrm{SO}_{4}$ feed was chemically attacked sufficiently to make desirable 


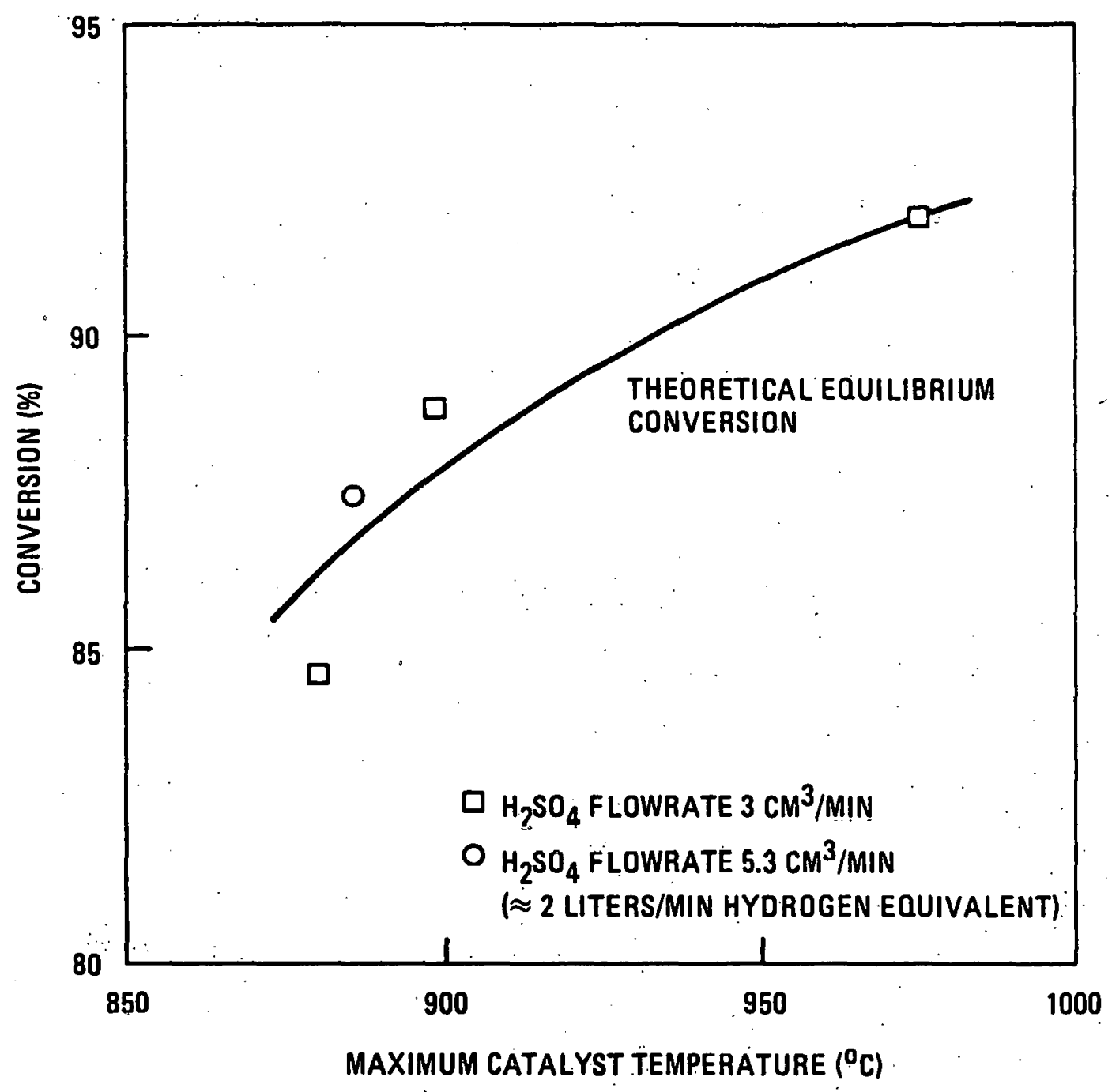

Fig. 10. Performance of bench-scale $\mathrm{H}_{2} \mathrm{SO}_{4}$ decomposition equipment 
the replacement with some other support material. Zirconia support pellets were thus replaced by a high silica $\left(2.53 \mathrm{wt} \% \mathrm{SiO}_{2}\right)$ aluminosilicate ceramic [ $? 1.27 \mathrm{~cm}(0.5 \mathrm{in.})$ diam spheres] with the tradename Denstone.* This support material showed only slight color change and surface roughening at the boiling interface after the first run and no discernible further change in subsequent runs. Additionally, a rust-pink band was seen deposited on the reactor tube wall after the first run with the Denstone support, although it was not discernible on the catalyst itself, and no change in catalyst activity was detected in any of the runs.

\subsubsection{Joint Operation of the Components of Subunit II. Currently,} the overall simultaneous operation of all Subunit II components was demonstrated at a flowrate equivalent to 2 std liters/min $\mathrm{H}_{2}$. All process steps functioned as designed until after 12 to $14 \mathrm{~h}$ operation when apparent cyclic thermal ratcheting of the large rough-surfaced spherical Denstone support pellets against the quartz reaction tube of the decomposer caused tube breakage. Use of smaller particles of irregular shape (possibly cracked Denstone spheroids) is expected to eliminate this problem.

\footnotetext{
* A product of Norton Company.
} 


\section{FUTURE WORK ON BENCH-SCALE UNIT}

Data gathering from Subunits I and II will continue to guide the integrated system operation, further demonstrate the flowsheet feasibility, and indicate improvements for scaling up to a larger demonstration unit. Functional testing of Subunit III will also begin. Additionally, extensive process improvements, suggested by the basic chemistry studies, are being considered for incorporation into the bench-scale system. These include replacing the gaseous hydrogen iodide decomposition equipment with a liquid HI decomposition section and adding a sulfuric acid concentration boost reactor. Currently, the sulfuric acid boost reaction bench-scale system has been constructed and some initial tests conducted. The HI liquid bench-scale system, on the other hand, has been designed, and the construction just begun. Both systems and the results for the sulfuric acid studies are described below. The two systems will be readied for eventual incorporation into the integrated bench-scale system.

\subsection{SULFURIC ACID CONCENTRATION BOOST REACTION BENCH-SCALE SYSTEM}

\subsubsection{Sulfuric Acid Concentration Boost Reaction Concept}

The concept of the sulfuric acid concentration boost reaction is detailed in Ref. 5. Briefly, the concept involves staging Eq. 1 to use the high iodine activity of pure molten iodine, In a countercurrent flow system, liquid iodine contacts the $\mathrm{H}_{2} \mathrm{SO}_{4}$ product of the standard $\mathrm{SO}_{2}-\mathrm{H}_{2} \mathrm{O}-\mathrm{I}_{2}$ reaction in the presence of high-activity $\mathrm{SO}_{2}$. This causes a redistribution of components and a general tendency for the reaction to create more $\mathrm{H}_{2} \mathrm{SO}_{4}$ and $\mathrm{HI}$. The $\mathrm{H}_{2} \mathrm{SO}_{4}$ product contains small amounts of $\mathrm{HI}$ and $\mathrm{I}_{2}$ and large amounts of $\mathrm{H}_{2} \mathrm{SO}_{4}$ and $\mathrm{H}_{2} \mathrm{O}$. In contact with pure liquid iodine, the $\mathrm{HI}$ tends to extract into the iodine phase with a small portion of the $\mathrm{H}_{2} \mathrm{O}$. The iodine tends to extract too, since $\mathrm{HI}$ 
helps it dissolve in the $\mathrm{H}_{2} \mathrm{SO}_{4}$ phase. Also, this process only slightly lowers the $\mathrm{H}_{2} \mathrm{O}$ activity, raises the iodine activity, and slightly raises the $\mathrm{H}_{2} \mathrm{SO}_{4}$ activity. This means that a reaction of $\mathrm{I}_{2}$ with $\mathrm{SO}_{2}$ and $\mathrm{H}_{2} \mathrm{O}$ is then favored, because some HI has to be made to bring the reaction system back into equilibrium. This generation of $H I$ is accompanied by a concomitant $\mathrm{H}_{2} \mathrm{SO}_{4}$ production. The iodine used to drive this countercurrent reaction is later used in the prime reaction (or is converted to normal $\mathrm{HI}_{x}$ product). No additional $\mathrm{H}_{2} \mathrm{O}$ reactant is required to accomplish this increased product yield, which is important since $\mathrm{H}_{2} \mathrm{O}$ dominates recycle energy demands. Initial single-stage experiments indicate that the treatment of the nominally $50 \% \mathrm{H}_{2} \mathrm{SO}_{4}$ aqueous lower phase formed via Eq. 1 results in attaining $256 \% \mathrm{H}_{2} \mathrm{SO}_{4}$.

\subsubsection{Description of Sulfuric Acid Concentration Boost Reaction Bench- Scale System}

This process is clearly best carried out in a countercurrent reactor where highest activity $\mathrm{I}_{2}$, initially substantially free of $\mathrm{HI}$ and $\mathrm{H}_{2} \mathrm{O}$, contacts the sulfuric acid of the highest possible activity with the least HI present. Precisely this situation develops in an infinitely staged countercurrent column. While creating an infinite number of stages is beyond experimental abilities, a system with an experimentally substantial number of stages could be created.

As part of the bench-scale studies, a staged countercurrent flow reactor column and ancillary equipment has been constructed. Figure 11 shows this system. It consists of the following: (1) a 10-stage stirred column in which the solutions passing from stage to stage are equilibrated by reaction and extraction, (2) a liquid $\mathrm{I}_{2}$ feed system, (3) a $50 \% \mathrm{H}_{2} \mathrm{SO}_{4}$ feed system, (4) an $\mathrm{SO}_{2}$ feed system, (5) an $\mathrm{SO}_{2}-\mathrm{H}_{2} \mathrm{SO}_{4}$ gas/liquid phase separator, and (6) appropriate reactant and product holding vessels. Iodine is added to the top of the column and flows down the column, where it is taken off as an $\mathrm{I}_{2}$-rich phase. Approximately $50 \% \mathrm{H}_{2} \mathrm{SO}_{4}$ is fed to the bottom of the column, causing the dilute light phase to flow up the column, being exposed to purer and purer $I_{2}$ as it traverses the 


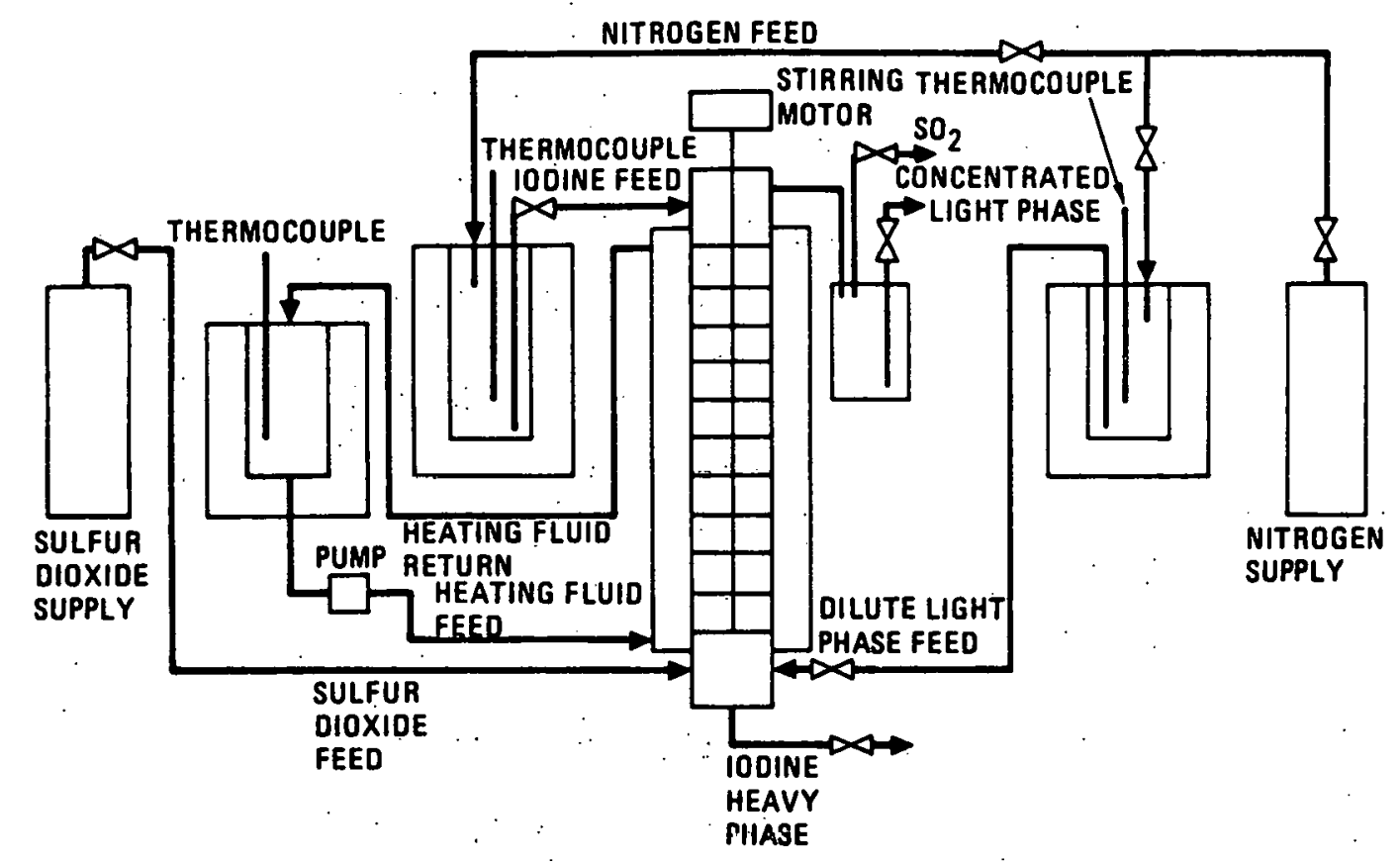

Fig. 11. Process flowsheet for reaction of iodine with upper-phase product 
column. A saturating flow of $\mathrm{SO}_{2}$ is added to the bottom of the column.

Figure 12 shows an individual stage of the column. The outer glass tube of this column, shown by diagonal cross hatching, has precision inner bore internal diameter, and the glass support ring is of closefitting precision external dimensions. Between the glass support rings are Teflon separators provided with small openings for phase flow. Stirring is accomplished by centrifugal pumping of liquid from the opening area near a separator to the spinning pump exit. A baffle in the lower portion of the cell reduces swirl. The stirrer/centrifugal pump is operated by a regulated variable-speed motor. The stirring rates and torques are metered. Every column stage should be operated at equilibrium, al though the column may be required to support a temperature gradient. Although operating in a temperature gradient (at the $I_{2}$ melting point at the top of the column and at the liquidus temperatures for $I_{2}$ solutions within the column) may be beneficial, all studies so far have been isothermal at a few degrees above the melting point of iodine for convenience.

\section{4:1.3. Results of Bench-Scale Testing of $\mathrm{H}_{2} \mathrm{SO}_{4}$ Concentration Boost}

Several experiments have been run with this equipment; most were to establish flow control information and to test certain reactor modifications. The apparatus has been operated so that meaningful data with fully describable flow and stirring parameters are available. During these studies, $50 \% \mathrm{H}_{2} \mathrm{SO}_{4}$ has been enriched in a number of experiments to $57 \% \mathrm{H}_{2} \mathrm{SO}_{4}$. The data indicate that about half of this increase was due to production of more $\mathrm{H}_{2} \mathrm{SO}_{4}$, as confirmed by $\mathrm{HI}$ found in the $\mathrm{I}_{2}$ phase. The other half comes from dehydration, which is valuable to the cycle energetics. Data do not yet indicate that steady-state operation on the $\mathrm{H}_{2} \mathrm{SO}_{4}$ boost reaction bench-scale unit has been attained. . Figure 13 illustrates this by the results for a typical run at a flow ratio of $9.8 \mathrm{G} \mathrm{I}_{2} / \mathrm{G} 50 \% \mathrm{H}_{2} \mathrm{SO}_{4}$ solution. Obviously, neither the concentration of $\mathrm{HI}$ in $\mathrm{I}_{2}$ nor the $\mathrm{H}_{2} \mathrm{SO}_{4}$ concentration has leveled out over the $60 \mathrm{~min}$ 


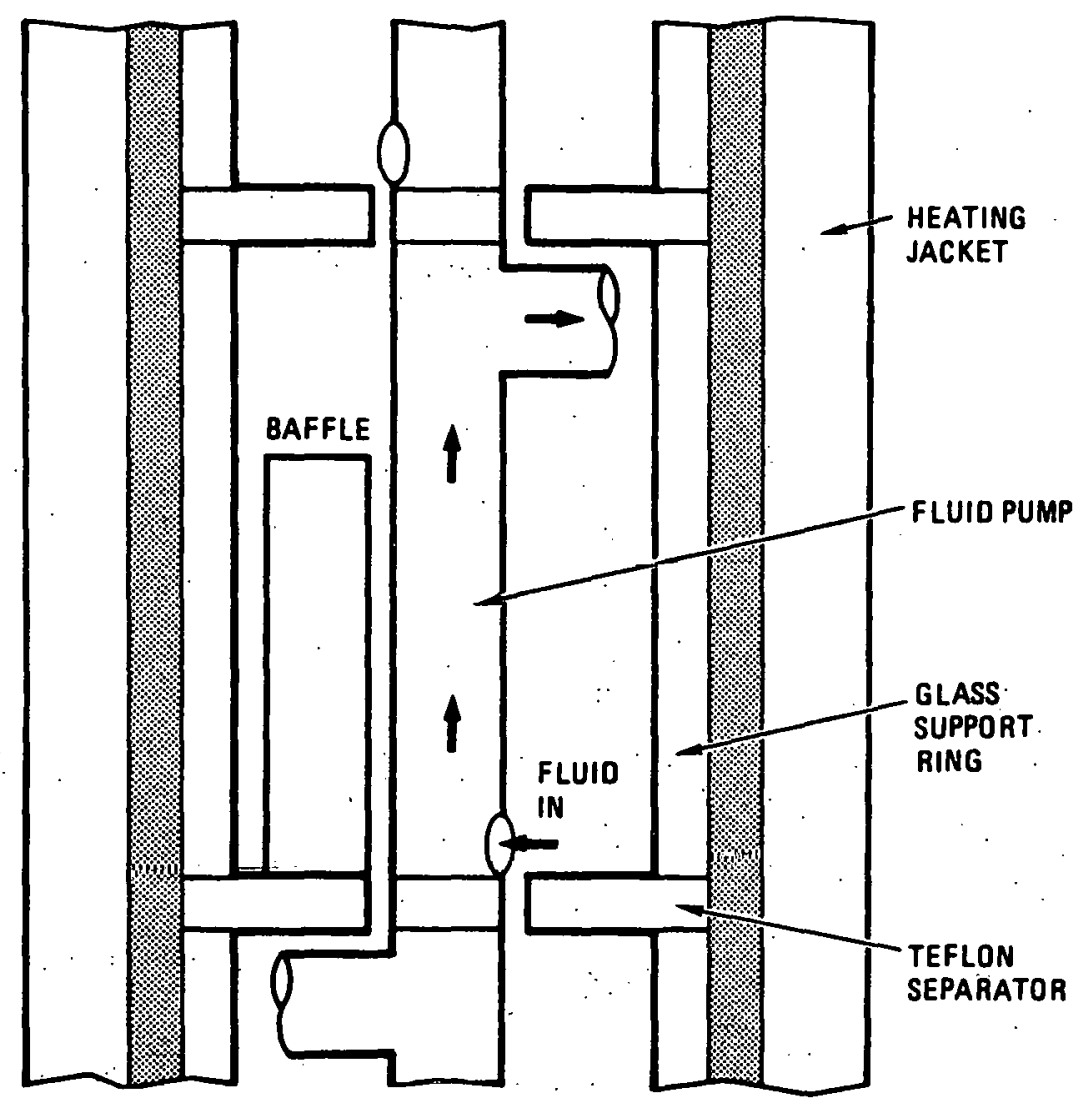

Fig. 12. Typical cell of $\mathrm{H}_{2} \mathrm{SO}_{4}$ boost column 
run, and steady-state conditions have not been reached. This is also the case for lower flowrates, al though steady. state seems more assured at longer than 140 min. An even higher concentration of $\mathrm{H}_{2} \mathrm{SO}_{4}$ in the present bench-scale unit is, therefore, limited by the amount of liquid $\mathrm{I}_{2}$ which can be processed at these flowrates. The flowrate ratio chosen to generate the Fig. 13 data is set by the main solution reaction, the requirement that the boost reaction be as effective as possible. As indicated in Fig. 13, experimental error is greater in measuring the $\mathrm{H}_{2} \mathrm{SO}_{4}$ concentration than the percent $\mathrm{HI}$ in $\mathrm{I}_{2}$.

\subsection{LIQUID HYDROGEN IODIDE DECOMPOSITION BENCH-SCALE SYSTEM}

\subsubsection{Liquid Hydrogen. Iodide Decomposition Concept}

References 3 and 10 detail the advantages of decomposing $H I$ in the liquid phase. This innovation results in enhanced conversion, since the chemical potential of the HI is maximized, while that of the $\mathrm{I}_{2}$ is stabilized at a value determined by the partial pressure of $\mathrm{I}_{2}$. This pressure is urders of magnitude less than the $\mathrm{H}_{2}$ pressure; because it dissolves in the HI liquid phase. Also, the process reactivity is at a high level, even for highly pregnant. $\mathrm{I}_{2} / \mathrm{HI}$. solutions, because the liquid. HI has intimate contact with the active surface of the catalyst. Nominally suggested operating temperatures are between $90^{\circ} \mathrm{C}$ and the approximate critical temperature of pure $\mathrm{HI}\left(i . e ., 150^{\circ} \mathrm{C}\right)$. Reference 10 describes the theoretical $\mathrm{H}_{2}$ equilibrium pressure levels, the expected conversion levels, and some results of a catalyst survey conducted in the liquid HI environment. Expected conversion levels are between $50 \%$ to $55 \%$, with the production of $\mathrm{H}_{2}$ at pressure levels equal to conventionally accepted pipeline pressures (i.e., $50 \mathrm{~atm}$ ) and higher. Incorporating liquid HI decomposition in the GA process flowsheet adds $3 \%$ to overall process efficiency due to the resulting recycle energy savings.

\subsubsection{Description of Liquid Hydrogen Iodide Decomposition Bench-Scale System}

Figure 14 is a schematic of the liquid $\mathrm{HI}$ bench-scale unit constructed 


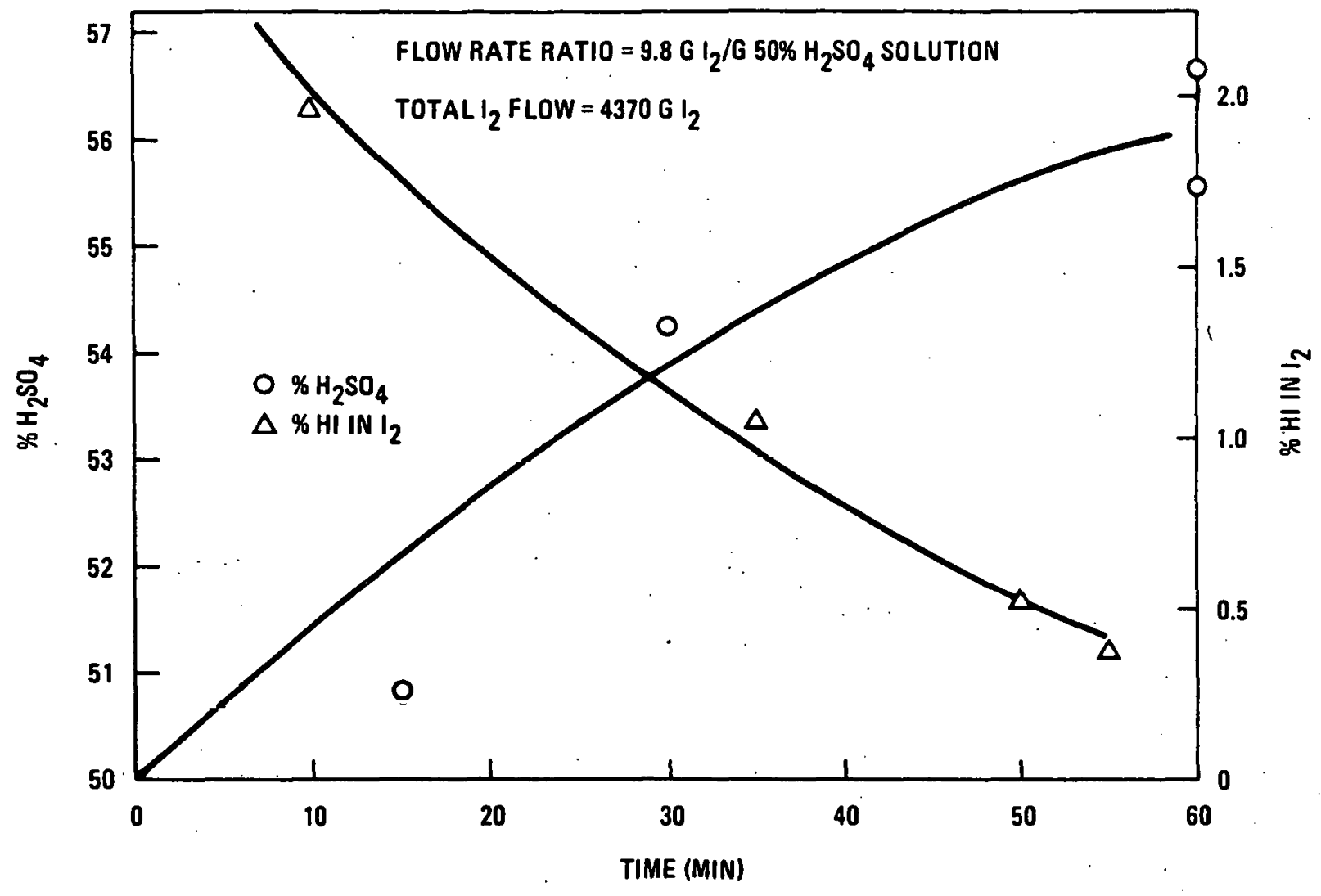

Fig. 13. Boost reaction approach to steady-state study $\left(120^{\circ} \mathrm{C}\right.$ nominal) 


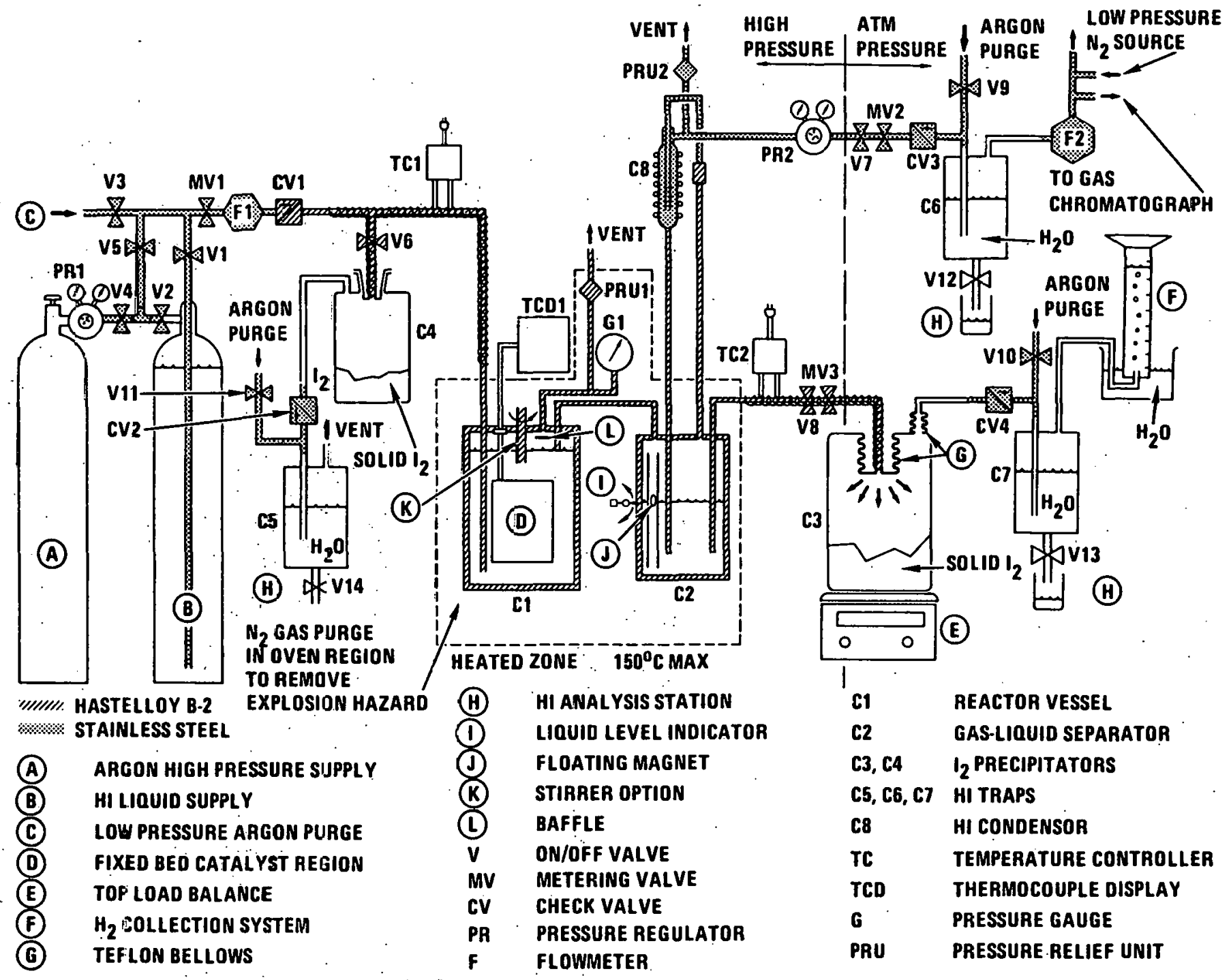

Fig. 14. Schematic of liquid HI decomposition bench-scale system 
to demonstrate liquid $H I$ decomposition at actual operating temperature and pressure $\left(90^{\circ}\right.$ to $150^{\circ} \mathrm{C}$ and 30 to $\left.80 \mathrm{~atm}\right)$. Previous studies were performed by batch, as reported in Refs. 3 and 10, and the results were extrapolated to the actual process conditions.

The liquid HI bench-scale unit is mainly constructed of stainless steel and Hastelloy Alloy B-2. Stainless steel is used for system parts exposed to nearly pure HI liquid or vapor at room temperature. Hastelloy Alloy B-2 is employed for system parts containing mixtures of $\mathrm{HI}$ and $\mathrm{I}_{2}$ liquid at temperatures up to $150^{\circ} \mathrm{C}$. These materials were chosen based on metallurgical studies performed at lower temperatures in simulated environments in the glass batch system used for the first-generation catalyst studies (Refs. 3 and 10) and in separate high pressure, high temperature batch tests in Hastelloy Alloy B-2 small volume ampules.

Dry liquid HI purchased in commercial pressure bottles is vapor transported to a stainless steel pressure bottle $B$. In doing so, the $H I$ is assured of being almost free of the $I_{2}$, which slowly accumulates to significant levels in storage and transportation. The almost pure liquid $\mathrm{HI}$ is then transported to the reactor $\mathrm{Cl}$ through appropriate control valves and flowmeters by pressurizing with argon gas to the required pressure. The reactor vessel is a 1-1iter Parr Instrument Corporation chemical bomb made of Hastelloy Alloy B-2 with the required top penetrations, as shown. Vessel $C-2$, which serves as a gas-liquid separator, is a smaller Hastelloy Alloy B-2 Parr chemical bomb. Both these vessels are sealed with Teflon gaskets.

Vessels C3 through C7 are all atmospheric pressure vessels constructed of glass. As indicated in Fig. 14, $\mathrm{C} 3, \mathrm{C} 6$, and $\mathrm{C} 7$ trap the unreacted $\mathrm{HI}$ and the product $\mathrm{I}_{2}$. Vessels $\mathrm{C} 4$ and $\mathrm{C5}$ are also $\mathrm{HI}$ and $\mathrm{I}_{2}$ traps, but they are used only in a back-flush operation upon shutdown of the equipment. Vessel $\mathrm{C} 8$ condenses HI vapor and returns it to the gas-liquid separator, alleviating the problem of contact between a highly rich corrosive HI gas environment and the pressure regulator PR2.. The pressure regulator reduces the pressure upstream of control valve MV2 to good 
flow control levels. All valves contacting $\mathrm{HI} / \mathrm{I}_{2}$ liquid are fabricated of Hastelloy Alloy B-2; Autoclave Engineers, Inc. is the supplier. Figure 14 indicates appropriate check valves, pressure relief units, and heat tracing.

The HI traps have the facility for removing aliquots for titration while the $\mathrm{I}_{2}$ formed is weighed on an electronic top load balance which can display the weight change on a chart recorder. Hydrogen flow is measured with the appropriate size rotameter once the HI component of the vapor is trapped. A gas chromatograph intermittently analyzes the $\mathrm{H}_{2}$ gas stream. A low-pressure $\mathrm{N}_{2}$ purge dilutes the $\mathrm{H}_{2}$ gas to below the explosive limit for release into the fume hood. The $\mathrm{H}_{2}$ collection system $\mathrm{F}$ measures the amount of $\mathrm{H}_{2}$ dissolved in the liquid $\mathrm{HI} / \mathrm{I}_{2}$ phase.

The reactor vessel ( $\mathrm{Cl}$ ), the gas-1iquid separator (C2), the bourdon gauge (GI), and pressure relief unit (PRVI) are housed in a forced convection oven with control from room temperature to $200^{\circ} \mathrm{C}$. All highpressure sections are contained within a high-impact-resistant plastic enclosure for operator protection. The oven is purged constantly with $\mathrm{N}_{2}$ gas to dilute any leaked $\mathrm{H}_{2}$ to below the explosion limit.

In many ways, the bench-scale unit construction is unique, mainly because of the corrosive fluids and the relatively high temperatures and pressures. Highest pressures and temperatures expected are $100 \mathrm{~atm}$ and $150^{\circ} \mathrm{C}$, respectively. A preheat on the incoming $\mathrm{HI}$, controlled by temperature controller $\mathrm{TCl}$, is required to speed up attaining steady-state conditions within the oven. The amount of power required to attain steady state is estimated to be only $\sim 50 \mathrm{~W}$ for the maximum flows used. This accounts for the estimated heat capacity effect, vaporization of the HI (1iq.), and the heat of reaction.

The reactor internal design is unique. The reaction makes a large amount of $\mathrm{H}_{2}$ gas internal to the catalyst bed in the presence of the liquid $\mathrm{HI}$ and liquid $\mathrm{I}_{2}$. Under such conditions, a certain loss of contact with the catalyst would be expected of the HI liquid in a one pass-through 
reactor design. Instead, the internal design, which will be tested first, involves a fixed catalyst bed with appropriate space around its sides and bottom. Hopefully, such a configuration will result in facile escape of the $\mathrm{H}_{2}$ gas bubbles from within the catalyst bed, with a resulting self-stirred motion of the surrounding liquid up through the bottom of the bed. This design will be tried initially, and the design will be optimized once results are obtained. The reactor vessel has a high-pressure magnetic drive stir option. The catalyst will be contained in a Hastelloy Alloy B-2 wire mesh cage for the above studies. The one pass-flow-through reactor will also be assessed by placing a machined Teflon plug into the reactor with the appropriate location of the cavity for the catalyst. For the flexibility required, the above reactor has been designed oversize. All components in the system have been designed to produce 4 std liters of $\mathrm{H}_{2} / \mathrm{min}$, and it is compatible with incorporation into the integrated bench-scale system later. 


\section{CONCLUSION}

This report presents preliminary results from the bench-scale testing of the GA sulfur-iodine thermochemical water-splitting cycle. These studies have verified the flowsheet design criteria for the specific subsections tested. Some modifications, not anticipated, were made in the system fluids handling. Most changes involved simple component redesign to handle the required flows and to obtain compatibility with specific corrosive environments. The most notable change, which will possibly impact future scaleup designs, is the discovery of a potential solids nucleation problem in certain $\mathrm{H}_{2} \mathrm{SO}_{4}$ solutions carrying small quantities of $\mathrm{I}_{2}$ and $\mathrm{HI}$. The problem is believed to be associated with the combined relatively long storage times of the synthetic feed solutions and the agitation of greatly oversized centrifugal pumps: These are inherent problems associated with the size of the bench-scale unit. Furthermore, the synthetic feed stock solutions were arbitrarily chosen close to the saturation limits of $\mathrm{HI}$ and $I_{2}$. These levels should be lower in the actual process.

Two innovations of the GA sulfur-iodide process, the sulfuric acid concentration boost reaction and the liquid $\mathrm{HI}$ decomposition process steps, were constructed as bench-scale units after batch testing. The $\mathrm{H}_{2} \mathrm{SO}_{4}$ boost reaction bench-scale unit operation indicated that sulfuric acid concentrations approached $57 \%$. This translates as additional $3 \%$ overall process efficiency, as calculated from the process flowsheets.

Overall, these precursory studies on isolated subsection operation within the bench-scale unit have further proven the technical viability of the GA sulfur-iodine process flowsheet design. 


\section{REFERENCES}

1. Russe11, J. L., et al., "Water-Splitting - A Progress Report," in the Proceedings of the 1st World Hydrogen Energy Conference, March 1976, Miami Beach, Florida, T. N. Veziroglu (ed.), University of Miami, Coral Gables, Florida, p. 1A-105.

2. Besenbruch, G. E., et al., "Hydrogen Production by the GA Sulfur Iodine Process, A Progress Report," in the Proceedings of the 3rd World Hydrogen Energy Conference, June 23-26, 1980, Tokyo, Japan, T. N. Veziroglu and T. Ohta (eds.), Pergamon Press, 1980.

3. O'Keefe, D. R., J. H. Norman, and D. G. Williamson, "Catalysis Research in Thermochemical Water Splitting," Catalysis Reviews 22, 3 (1980).

4. Norman, J. H., et al., "Chemical Studies on the General Atomic Sulfur-Iodine Thermochemical Water-Splitting Cycle," in the Proceedings of the 2nd World Hydrogen Energy Conference, Zurich, Switzerland, August 27-24, 1978, T. N. Veziroglu and W. Seifritz (eds.), Pergamon Press, 1978, p. 513.

5. Norman, J. H., et al., "Studies of the Sulfur-Iodine Thermochemical Water-Splitting Cycle," in the Proceedings of the 3rd World Hydrogen Energy Conference, June 23-26, 1980, Tokyo, Japan, T. N. Veziroglu and T. Ohta (eds.), Pergamon Press, 1980.

6. DeGraaf, J. D., et al., "Engineering and Bench-Scale Studies on the General Atomic Sulfur-Iodine Thermochemical Water-Splitting Cycle," in the Proceedings of the 2nd World Hydrogen Energy Conference Zurich, Switzerland, August 21-24, 1978, T. NT. Veziroglu and W. Seifritz (eds.), Pergamon Press, 1978, p. 545.

7. Trester, P. W., and S. S. Liang, "Material Corrosion Investigations for the General Atomic Sulfur-Iodine Thermochemical Water-Splitting Cycle," in the Proceedings of the 2nd World Hydrogen Energy Conference Zurich, Switzerland, August 21-24, 1978, T. N. Veziroglu and W. Seifritz (eds.), Pergamon Press, 1978, p. 2113. 
8. Caprioglio, G., K. McCorkle, and R. Sharp, "Closing the Loop for the Sulfur-Iodine Cycle," in Hydrogen Production and Marketing, based on a symposium sponsored by the Division of Industrial and Engineering Chemistry at the ACS/CSJ Chemical Congress, Honolulu, Hawaii, April 2-6, 1979, W. N. Smith and J. G. Santangelo (eds.), ACS Symposium Series 116, 1980, p. 323.

9. "Thermochemical Water-Splitting Cycle, Bench Scale Investigations and Process Engineering, Annual Report, February-December 1977," DOE Report GA-A14950, General Atomic Company, April 1978.

10. "Thermochemical Water-Splitting Cycle, Bench Scale Investigations and Process Engineering, Annual Report, October 1978-September 1979," DOE Report GA-A15788, General Atomic Company, March 1980.

11. Gimitro, J. I., and T. Vermeulon, "Vapor-Liquid Equilibria for Aqueous Sulfuric Acid," University of California, Radiation Laboratory Report UCRL-10886, June 1963.

12. Treybal, R. E., Mass Transfer Operations, McGraw Hill Book Company, New York, 1955.

13. JANAF Thermochemical Tables, Dow Chemical Company, Midland, Michigan, December 1976. 


\section{ACKNOWLEDGEMENTS}

Thanks are due to J. S. Rode, L. E. Jolley and S. A. Dunlap for some of the shakedown efforts on Subunits I and II. Thanks are also due to $P$. W. Trester for input on the design and construction of the liquid hydrogen iodide decomposition bench-scale system from the metallurgical viewpoint. 


\section{ABSTRACT}

Portions of a bench-scale model of a sulfur-iodine thermochemical water-splitting cycle have been operated at General Atomic Company as part of a comprehensive program to demonstrate the technology for hydrogen production from nonfoss 11 sources. The hydrogen program is funded by the U.S. Department of Energy, the Gas Research Institute, and General Atomic Company. The bench-scale model consists of three subunits which can be operated separately or together and is capable of producing as much as 4 std liters/min $\left(6.7 \times 10^{-5} \mathrm{~m}^{3} / \mathrm{s}\right.$ at standard conditions) of gaseous hydrogen. One subunit (main solution reaction) reacts liquid water, liquid iodine $\left(\mathrm{I}_{2}\right)$ and gaseous sulfur dioxide $\left(\mathrm{SO}_{2}\right)$ to form two separable liquid phases: 50 wt \%. sulfuric acid $\left(\mathrm{H}_{2} \mathrm{SO}_{4}\right)$ and a solution of iodine in hydriodic acid $\left(\mathrm{HI}_{x}\right)$. Another subunit $\left(\mathrm{H}_{2} \mathrm{SO}_{4}\right.$ concentration and decomposition) concentrates the $\mathrm{H}_{2} \mathrm{SO}_{4}$ phase to the azeotropic composition, then decomposes it at high temperature over a catalyst to form gaseous $\mathrm{SO}_{2}$ and oxygen. The third subunit ( $H I$ separation and decomposition) separates the $\mathrm{HI}$ from water and $\mathrm{I}_{2}$ by $\mathrm{ex}=$ tractive distillation with phosphoric acid $\left(\mathrm{H}_{3} \mathrm{PO}_{4}\right)$ and decomposes the $\mathrm{HI}$ in the vapor phase over a catalyst to form $\mathrm{I}_{2}$ and product hydrogen. This paper presents the results of on-going parametric studies to determine the operating characteristics, performance, and capacity limitations of major components. 


\section{INTRODUCTION}

The recent realization that the earth's fossil fuel resources cannot inexhaustibly supply society's needs has prompted investigating many alternative fuel sources. One alternative fuel source is hydrogen from water splitting. Hydrogen, when combined with solar or nuclear heat sources is a renewable, portable fuel from water, which can be stored as a gas, liquid, or hydride, depending on the application. A hydrogen economy appears to have many benefits, and researchers around the world have recently devoted considerable effort to developing viable processes for the economic largescale production of hydrogen fuel from water. The General Atomic Company (GA) sulfur-iodine process is a thermochemical water-splitting approach currently being developed and assessed.

The program to investigate thermochemical water splitting using the high-temperature gas-conled reactor (IITGR) ds a heat source has been underway at GA since October 1972. Current program participants are the Gas Research Institute (GRI), which carries on the sponsorship of the American Gas Association (AGA), the U.S. Department of Energy (DOE), and GA. Northeast utilities Service Company and Southern California Edison Company previously participated.

The GA sulfur-iodine cycle was first described in the open literature by Russel1 (Ref. 1). Reference 2 is a recent overview of the entire program effort. The chemical basis for thermochemical water splitting is contained in a review paper on catalysis (Ref. 3), and Refs. 4 and 5 survey the chemical studies performed to establish the process direction. Reference 6 gives specific details on the program process engineering. Reference 7 reports on the materials investigation. 